Colloque C2, suppl. au Journal de Physique II, Vol. 1, septembre 1991

\title{
CHEMICAL VAPOUR DEPOSITON - A REVIEW OF 25 YEARS EXPERIENCE
}

\author{
E. FITZER \\ Institut fuer Chemische Technik der Universitaet Karlsruhe, \\ Kaiserstrasse 12, D-7500 Karlsruhe 1, Germany
}

\begin{abstract}
This paper describes studies of CVD processes of technical relevance, in which some unusual and unexpected phenomena have been observed. It offers, furthermore, explanations, solutions to problems, and ways of mathematical modelling. At the start, reaction and diffusion layers on iron and on molybdenum are considered. Because of overlapping metallurgical difficulties, the further studies are restricted to CVD overlay coatings. The "aluminizing" of the cooling channels in turbine blades made of $\mathrm{Ni}$ based superalloys by the subchloride process and $\mathrm{MaSi}_{2}$ deposition on refractory alloys with diffusion barriers are described.
\end{abstract}

$\mathrm{SiC}$ deposition with carbon excess on carbon substrates with lamella structure is explained by an oscillating chemical reaction. For the $\mathrm{SiC}$ deposition on the inner surface of porous substrates a mathematical model is offered. For CVD of layers on monofilaments in continuously moving carbon fibre bundles a successfully applied equipment is described as well as experimental results and a mathematical model for a quantitative consideration of the complex deposition process.

Concerning pyrocarbon by CVD, spiral and whisker growth has been found, nucleated by dislocations in the surface. The low pressure deposition of diamond is discussed.

Finally, CVD of superconducting films is described, both the classical $\mathrm{Nb}(\mathrm{C}, \mathrm{N})$, as well as the YBCO oxides. They are discussed from viewpoint of process parameters and their influence on the product properties. The review closes with the most recent studies of $\mathrm{ZrO}_{2}$ composite layers, mady by $\mathrm{CVD}$, for application as heat barriers.

\section{Introduction}

There are three basic requirements for controlled CVD:

1. Suitable chemistry in the gas phase; i.e. firstly the chemical thermodynamics of the volatile educts, which controls the limits for the reaction parameters such as partial pressure and temperature for the envisaged deposition, and secondly the chemical kinetics of the deposition reactions.

2. Knowledge of the transport phenomena, concerning the gas flow in the reactor and of the diffusion of the educt species in the gas film surrounding the surface of the substrate. Diffusion is of particular importance in the case of limited gas flow in porous substrates. Gas flow is decisively influenced by the experimental arrangement.

3. The chemical behaviour of the substrate. Predominantly in the case of metallic substrates secondary reactions with solid deposits can lead to reaction or diffusion layers. In the case of the deposition of overlay coatings on non-reactive substrates the substrate surface can become important as nuclei for the vapour deposition of the solid.

The combined influence of all these problems is the well-known reason for the complexity of CVD-processes. In the following sections some technologically relevant experiences are reported, demonstrating the importance of these three fundamental requirements. This paper cannot replace a textbook on CVD. It will only show some unexpected phenomena and methods to overcome the problems in the fields mentioned above.

\section{CVD on reactive substrates by which reaction and diffusion layers are formed}

In the late thirties interest in chromium diffusion layers on iron based alloys arose in Germany for political and economic reasons. The process called "inchromization" was technically applied as pack cementation, but was studied intensively as 
a CVD process from chromium chloride and hydrogen. The chemical preconditions of both the chemical thermodynamics of chromium and hydrogen in the gas phase and the metallurgy of the binary system chromium/iron are extremely suitable, the latter because of the similarity of iron and chromium atoms and the formation of unlimited solid solutions.

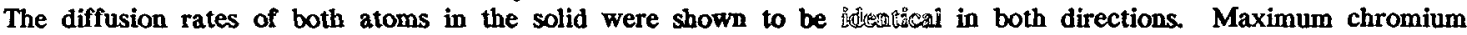
enrichment up to $30 \%$ has been achieved with a typical decrease of chiromium concentration towards the inner part of the substrate (1). The process was applied to the fabrication of corrosion resistant surface layers without any problems concerning the adhesion of the chromium rich diffusion layer to the substrate.

In the late forties my first contact with CVD studies was the "siliconizing" of iron, intended to replace chromium chloride by the cheaper silicon chloride (2). Iron/silicon alloys with a silicon content of about 14 wt\% are well known as being chemically resistant, but also as being extremely hard and brittle. It became known at this time that during the last years of World War II, surface "siliconizing" was under discussion for surface hardening of armor plates. The intention of our studies in the fifties was the fabrication of corrosion resistant surface layers on unalloyed iron.

We were able to show that "siliconizing" of iron is less favourable than "inchromizing", mainly because of the Fe/Si intermetallics which are formed near the surface and cause asymmetric diffusion behaviour of the atoms in such layers. The diffusion rate of iron outwards into the silicide layer is much higher than the inward diffusion of silicon into the substrate. The disadvantageous consequences are known as the Kirkendall effect; that is the formation of a pore zone parallel to the surface which causes spallation of the surface layer (2).

However, it was found already in the fifties that these unfavourable metallurgical conditions in "siliconizing" are limited to iron as substrate but are not observed in nickel and nickel based alloys (3) and in refractory metals like molybdenum, tungsten or tantalum (4). Also in latter case, CVD of silicon from $\mathrm{SiCl}_{4}$ and hydrogen gas forms directly the intermetallic compound by reaction of the chemical vapour deposited silicon with the substrate.

The interesting technical effect of $\mathrm{MoSi}_{2}$ layers deposited on molybdenum is their absolute resistance against high temperature oxidation up to $1700^{\circ} \mathrm{C}$. The application of these $\mathrm{MoSi}_{2}$ reaction layers, however, is limited because of a subsequent diffusion reaction during application at high temperatures in which intermetallic silicides with lower silicon contents are formed and which are not resistant against high temperature oxidation (see Fig. 5). From this it follows that diffusion barriers are needed such as tungsten, tantalum or niobium (5). Under these circumstances the CVD of only one component undergoing a secondary reaction with the substrate to form the protective layer is not applicable. Overlay coatings by CVD are the only suitable solution for such problems.

\section{Qverlay coatings by CVD}

This section is concerned with some of our studies on overlay coatings beginning in the sixties. Only cases with unexpected results which do not follow the regular textbook knowledge will be reported.

\subsection{Al deposition on Ni based super alloys via the subchloride process - CVD with inverse temperature gradient (6)}

Usually in physical vapour deposition processes the volatile species are formed at temperatures higher than those of the deposition. PVD is similar to a condensation process on the surface of the substrate. In CVD processes the situation is reversed; the volatile compounds are formed at temperatures lower than those of the substrate during deposition where the thermal decomposition of the volatile educts occurs.

The CVD aluminizing process via the subchloride route uses the same temperature gradient as the PVD-processes. The process is based on the chemical instability of the subchloride AlCl at lower temperatures and its formation from aluminium trichloride at higher temperatures. The partial pressure of the subchloride $\mathrm{AlCl}$ as a function of temperature is shown in Fig. 1.

From the viewpoint of thermodynamics the usually observed influence of the reduction of the chloride by hydrogen can be neglected due to the formation of NiAl at the surface. It was found, however, that the reaction is considerably accelerated by hydrogen (see Fig. 2).

The technical background of this study was the "aluminizing" of nickel based turbine blades with cooling channels. Today, "aluminizing" is technically performed by the plasma spray process exclusively, but this spray method cannot be applied to the inner surface within the cooling channels.

Fig. 3 shows the experimental arrangement for a tubular hot wall deposition reactor. Part (a) shows the temperature distribution in the tubular furnace, and part (b) the aluminium subchloride formation from aluminium trichloride and molten aluminium at lower temperatures. Part (c) shows the arrangement of the turbine blades within the tubular 


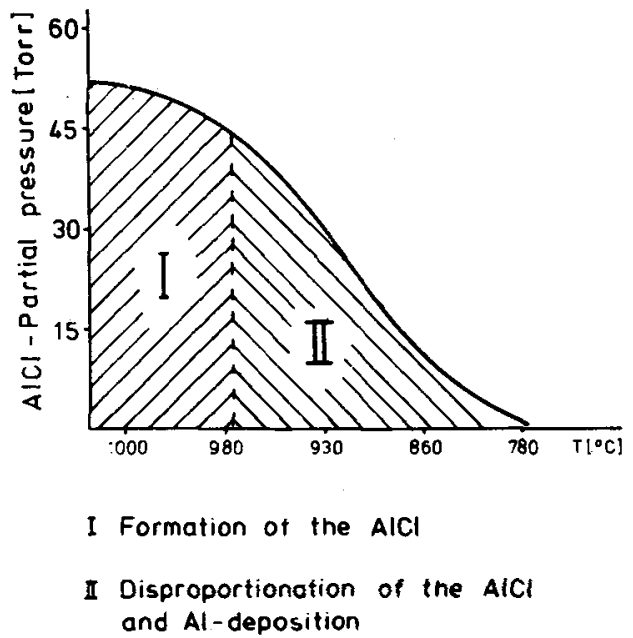

Fig. 1: Dependence of $\mathrm{ACl}$ partial pressure on temperature $\mathrm{I}-\mathrm{AlCl}$ formation; II - Al deposition from AlCI

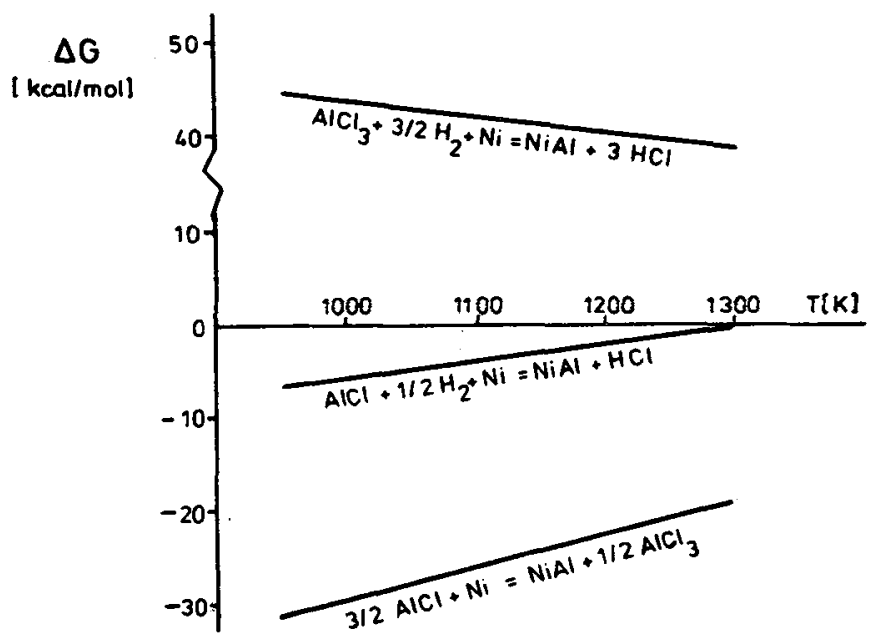

Fig. 2a: Thermodynamics of aluminium deposition from Al chlorides

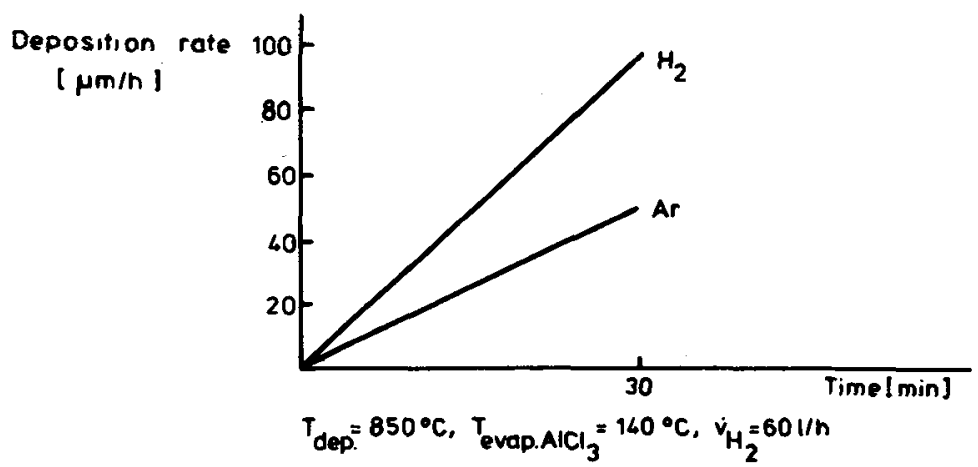

Fig. 2b: Deposition rate of $\mathrm{Al}$ 
(a)

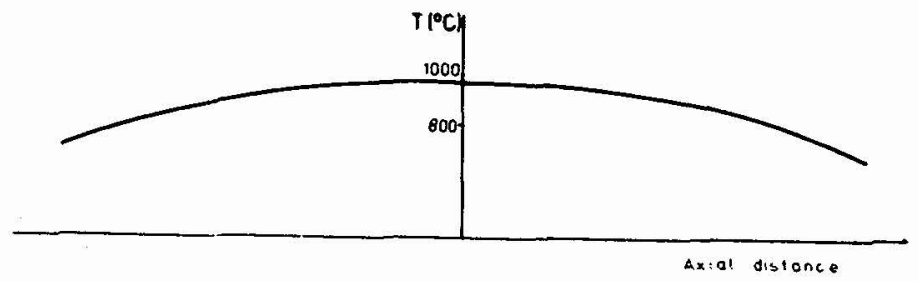

Temperature profile of a fubular reactor

(b)

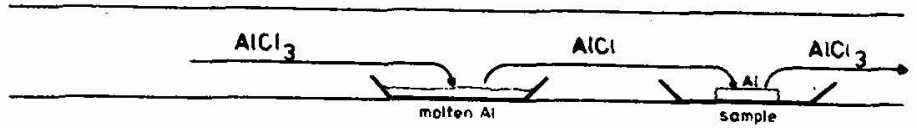

(c)

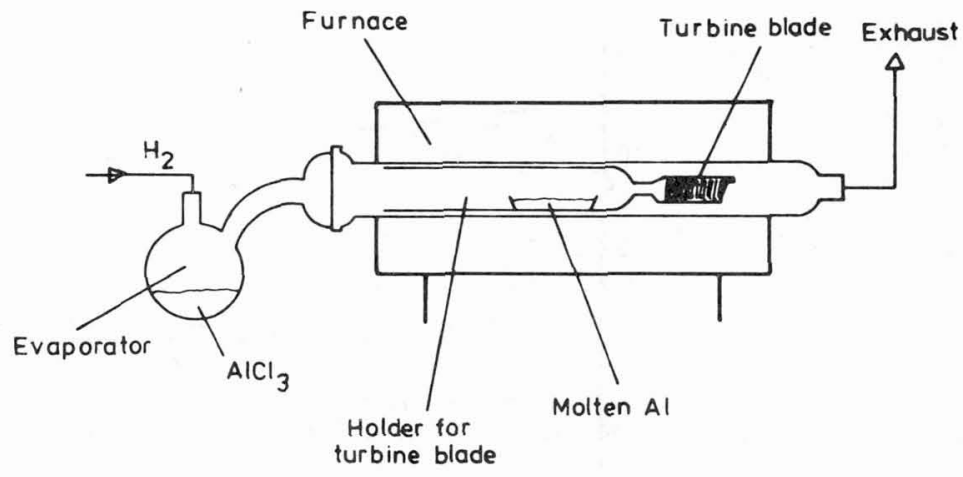

Fig. 3: a) Temperature profile; b) Schematic of the subchloride process c) The position of the blades as substrates

Fig. 4:

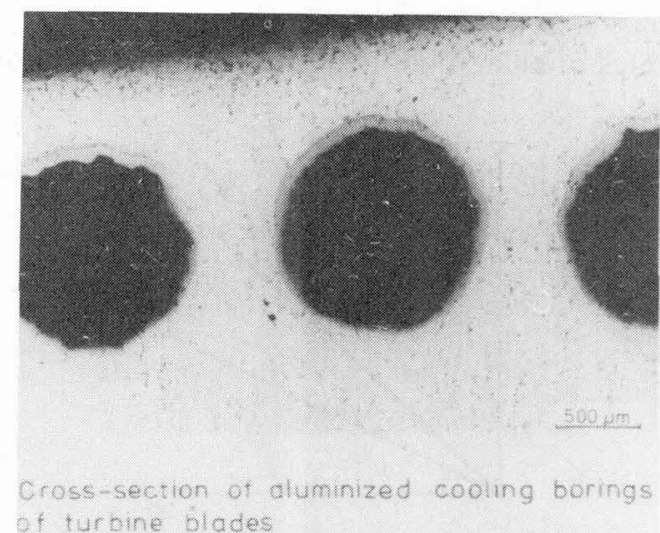
thine orades 
furnace with the gas flow through the cooling channels. The results for aluminizing of the cooling channels are shown in Fig. 4. The deposition temperature was about $900^{\circ} \mathrm{C}$. This is a temperature which does not cause any metallurgical damage to the nickel based super alloys.

In principle, one can deposit aluminium layers at low temperatures of the substrate with aluminium bromide as educt. It was shown, however that the subchloride process is much more favourable than the bromide process because no attack by a volatile aggressive halogen hydrogen by-product occurs.

\subsection{Deposition of the binary intermetallic $\mathrm{MOSi}_{2}$ - an irregular educt ratio of both components in the gas phase}

The need to deposit the oxidation resistant binary intermetallic $\mathrm{MoSi}_{2}$ without any contribution of the solid/solid reaction with the substrate has been mentioned above. Therefore we studied the direct deposition of the binary intermetallic $\mathrm{MOSi}_{2}$ by simultaneous vapour deposition of molybdenum and silicon.

There are several intermetallics in the binary system $\mathrm{Mo} / \mathrm{Si}$ with practically no area of solubility in the solid state (see Fig. 5). Only the intermetallic $\mathrm{MoSi}_{2}$ is of technical interest.

The conditions necessary for CVD in order to obtain the specific composition of the silicide in a hot wall arrangement are shown in 3-dimensional diagrams in Fig. 6 (7), which gives results of experimental studies and not of theoretical calculations. The Si:Mo ratio in the gaseous phase is used as the abscissa of the 3-dimensional plots whilst the Si:Mo ratio in the resulting deposit is plotted as ordinate. The deposition temperature is given by the vertical height of the 2-dimensional plots. As can be seen, high deposition temperatures of at least $1000^{\circ} \mathrm{C}$ and a large excess of silicon in the gas phase with a $\mathrm{SiCl}_{4}: \mathrm{MoCl}_{5}$ ratio of at least 3 at $1400^{\circ} \mathrm{C}$ and 6 at $1000^{\circ} \mathrm{C}$ are required to obtain the oxidation resistant disilicide as deposit.

$\mathrm{MoSi}_{2}$ layers can be deposited by this method, but in order to achieve high deposition rates high partial pressures of the gaseous educts must be used. At high temperatures, however, coarsely grained columnar structures will result, whereas a high educt concentration causes porous deposits because of preferred gas phase nucleation. These limitations in the CVD of $\mathrm{MOSi}_{2}$ preclude effectively the application of the process to inpore deposition; for instance the gas phase impregnation of porous substrates or the deposition of surface layers in cooling channels as described above.

One can also deposit niobium diffusion barriers as they are needed for long term applications of $\mathrm{MoSi}_{2}$ coatings at high temperatures. The CVD conditions are added in Fig. 6 as part (b). However, the CVD-process is very uneconomic in this case. We have shown that for technical applications the plasma spraying of $\mathrm{MoSi}_{2}$ overlay coatings with a subsequent hot pressing step offers more advantages (8). The spraying of overlay coatings, however, is limited to simple substrate geometries.

\subsection{CVD of SiC surface coatings - a study of nucleation}

Similar to the intermetallic $\mathrm{MOSi}_{2}$, the stoichiometric refractory compounds $\mathrm{SiC}$ and $\mathrm{Si}_{3} \mathrm{~N}_{4}$ guarantee an excellent protection against high temperature oxidation up to $1500^{\circ} \mathrm{C}$ because of the high silicon content and the formation of so-called self-healing $\mathrm{SiO}_{2}$ layers with a good barrier effect against oxygen diffusion at high temperatures.

$\mathrm{SiC}$ layers are formed mostly by simultaneous vapour deposition of silicon and carbon from the methylchlorosilanes where the ratio of the elements silicon and carbon is controlled by the type of molecules. Mixtures of silanes or chlorosilanes and hydrocarbons can also be used. The assumption that a stoichiometric $\mathrm{Si} / \mathrm{C}$ ratio in the gas phase will result in a stoichiometric $\mathrm{Si} / \mathrm{C}$ deposit is fulfilled much better than in the above mentioned case of molybdenum silicide, but it is not really true in all cases. For example, monomethyl trichlorosilane tends to form deposits with an excess of silicon. On the other hand, methylchlorosilanes with an excess of carbon such as dimethyl- or trimethylchlorosilane must form some kind of deposit with excess carbon or alternatively carbon containing volatile by-products.

Silicon carbide is a stoichiometric compound without any carbon solubility as shown in Fig. 7 . It cannot be predicted how excess carbon will be distributed in the deposit or whether the excess carbon will form volatile by-products only.

As a first step we studied the solid products and calculated the yield of $\mathrm{SiC}$ and of excess carbon from various methylchlorosilanes as shown in Fig. 8. At lower temperatures, only silicon carbide is found and the excess carbon is lost as volatile carbon containing by-products. This result shows the relative stability of the gaseous carbon and hydrogen containing species as compared with the rapid rate of the $\mathrm{SiC}$ deposition reaction between the hydrogens of the methyl groups and the chlorine substituents from trimethylchlorosilane in layers formed from dimethylchlorosilane at higher temperatures. 


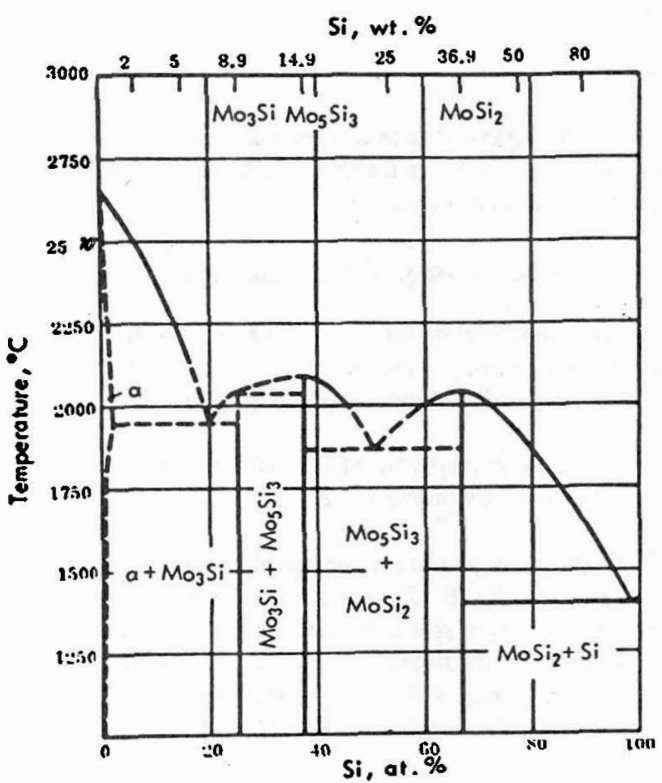

Fig. 5: Phase diagram for the Mo/Si system
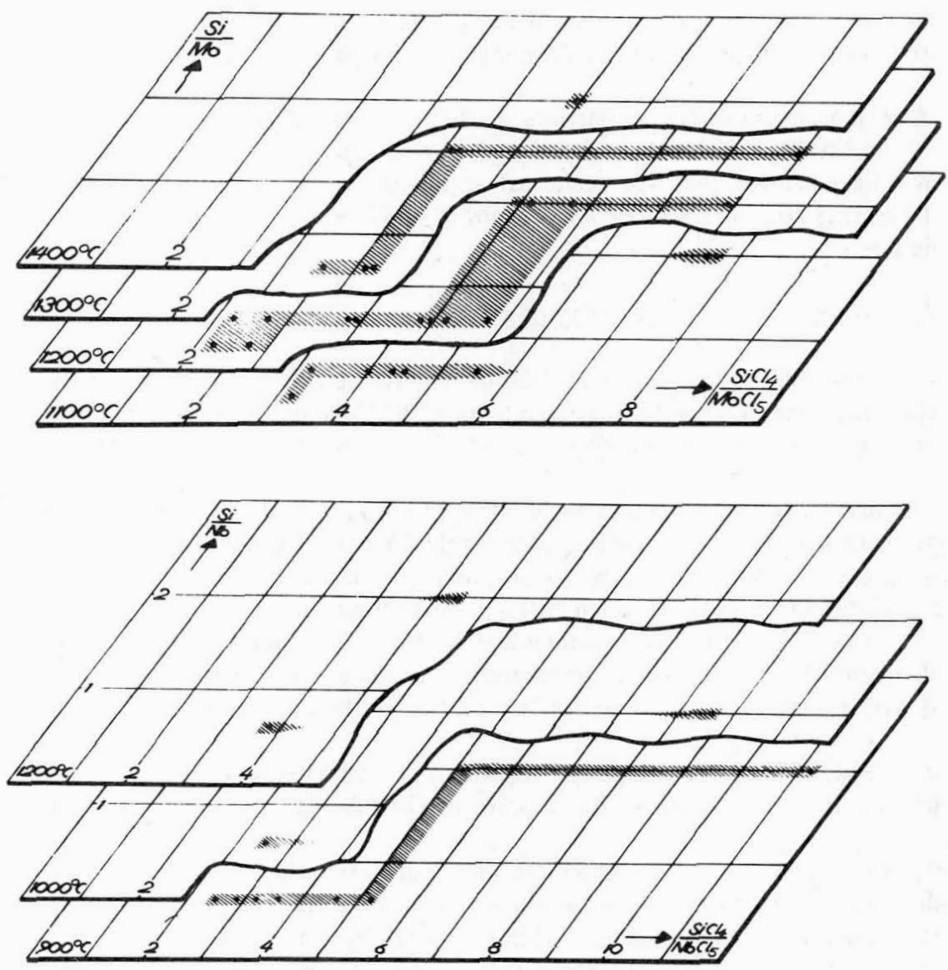

Fig. 6: Molar ratio of the gaseous educts (abscissa) against atomic ratio in the deposit for $\mathrm{CVD}$ of $\mathrm{Mo}$ and $\mathrm{Nb}$ 


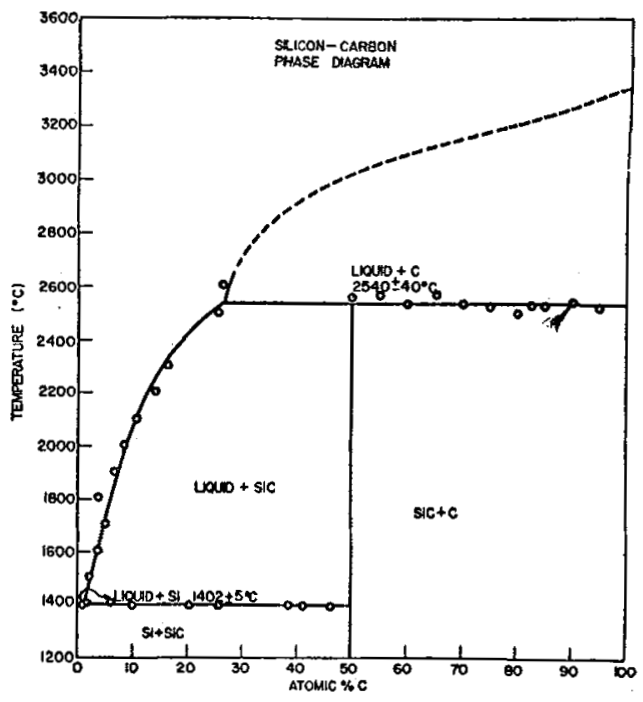

Fig. 7: Phase diagram for the Si/C system

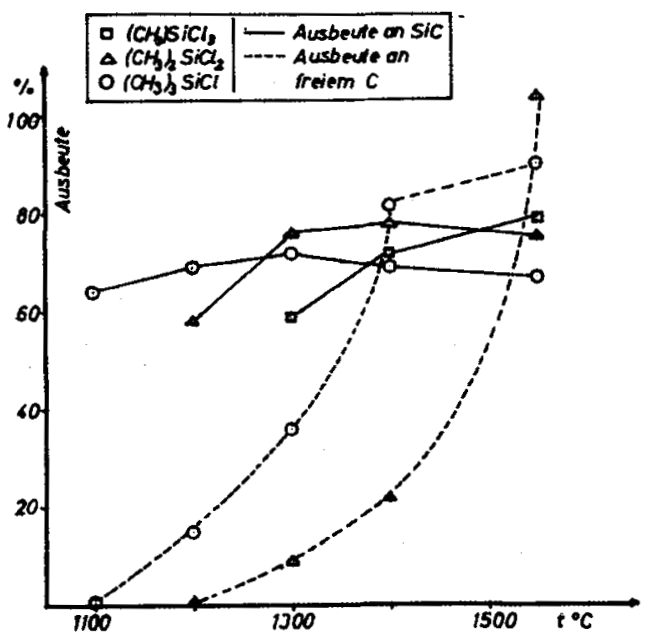

Fig. 8a: Results for the composition of deposits ( $\mathrm{SiC}$ and $\mathrm{C}$ ) from various educts

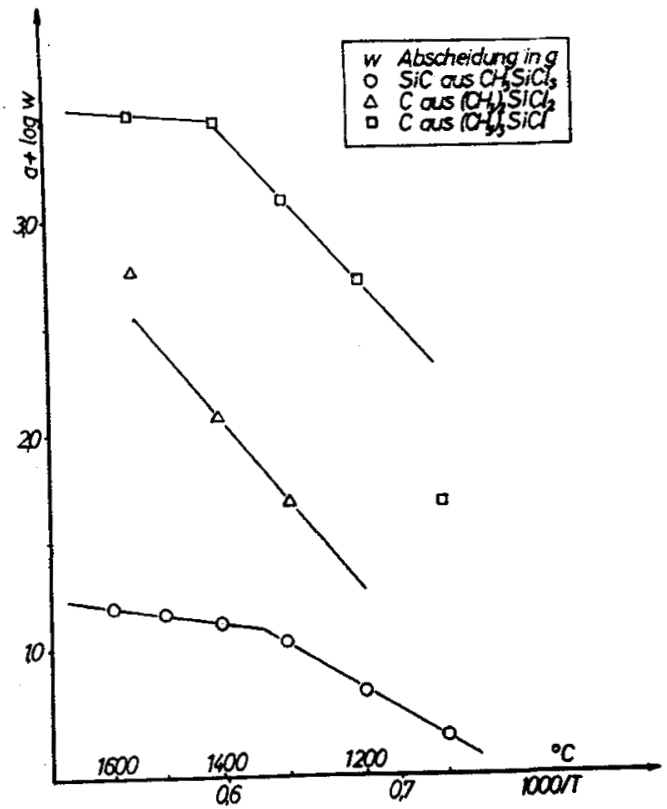

Fig. 8b: Arrhenius plots for $\mathrm{SiC}$ deposition 
For the three different silanes strongly different reaction rates are observed. The fastest decomposition is found for the trimethylchlorosilane; i.e a silane with the highest C/Si ratio, whereas the "stoichiometric" trichloromethylsilane decomposes rather slowly. As far as the distribution of excess carbon is concerned (i.e. the morphology of the deposit) surprisingly a lamellar structure has been found with alternating silicon carbide/carbon layers as shown in Figs. $9 \mathrm{a}$ and $9 \mathrm{~b}$. These relatively thin layers were identified by electron beam microanalysis (9).

The question is what is the mechanical behaviour of deposits with such a lamellar structure? Fig. 10 shows the result of impact damage - a clear delamination. The explanation for this lamination in the deposit is a dynamic instability during the chemical deposition reaction by the hindered or retarded nucleation in the gas film near the surface (10). Oscillating chemical reactions are known in chemical engineering, Fig. 11 shows as an example the oscillation in product formation and temperature as published for the block polymerization of polystyrene in a technical back mixed reactor. As another example, the lower part of the figure shows ascillations observed during the decomposition of $\mathrm{N}_{2} \mathrm{O}$ in a laboratory reactor caused by partial back mixing of the feed. Such oscillations in homogeneous reactions either in liquids or in gases are caused mainly by exothermic effects and the back mixing of new educts with preferred products under steady state conditions.

In the observed case of lamellation in CVD of $\mathrm{SiC}$ the back mixing occurs in the gas film on the surface, when nucleation for the growth of a deposit is retarded. Then gaseous species, formed by pyrolysis and escaping volatile by-products, will be back mixed with arriving new parts of the gaseous educt. As was shown in Fig. 8b, SiC formation occurs very fast as the first product in the complex decomposition of the methyl chlorosilanes in any case. It is also known, from the deposition of isotropic pyrolytic carbon, that $\mathrm{SiC}$ forming silicon chlorides are added to form nuclei for the growth of pyrolytic carbon on the substrate. Isotropic pyrocarbon deposits can only be achieved by such heterogeneous nucleation.

The spontaneous deposition of solid $\mathrm{SiC}$ in the lamella structure causes an impoverishment of the SiC forming species in the gas film, whereas additional hydrocarbon radicals are formed as by-product of the SiC-formation. Also the by-product $\mathrm{HCl}$ is known to act as a catalyst in carbon deposition from hydrocarbons. Thus, pyrocarbon nucleation is both initiated and retarded as compared with the $\mathrm{SiC}$ nucleation. The growth of pyrocarbon deposits now causes impoverishment of the species in the gas film, which can form pyrocarbon. Because of this carbon deposition, a gradient in concentration of educts is now formed between the bulk gas phase and the laminar gas film near the surface of the substrate, which is the driving force for enhanced diffusion through the gas film in the surface layer.

Summarizing, the first supersaturation and nucleation is reached by the SiC forming species, nucleation causes retarded deposition of carbon and so on. This lamella formation can be explained qualitatively without any thermal effects.

One can expect thickening of the lamella at reduced pressure because of an increasing mean free path of the molecules. This has been observed experimentally. Lamella formation disappears completely at total pressures below 40 torr. This finding can be taken as confirmation of the proposed explanation for the heterogeneous lamella structure.

Such lamella formation has also been found experimentally with dimethyl- and trimethylchlorosilane in a fluidized bed reactor for the coatings on granular carbon substrates. This can be explained in the same way. The reasons for this fluctuation in chemical reactions are back mixing in the gas film surrounding the surfaces and large differences in supersaturation needed for nucleation of the different compounds forming the solid, as well as the building up of the necessary supersaturation by diffusion.

By estimating the mean free paths of methylchlorosilane at various pressures one can conclude that a gas film thickness much below $1 \mu \mathrm{m}$ can act as a diffusion barrier for the educt species. In the fluidized bed reactor this lamellation is not influenced by changing flow conditions within the fluidized bed but only by changing of the reaction parameters such as pressure, concentration and temperature.

The question may arise whether such oscillations in vapour deposition reactions are limited to silicon carbide with co-deposition of excess carbon. It was found that a very similar behaviour is observed for simultaneous boron carbide and carbon deposition (11) and furthermore with excess carbon (12). In the latter case, we are able to demonstrate that deposited titanium carbide acts as nuclei for the excess carbon via solid catalysis.

\subsection{Gas phase infiltration - demonstration and modelling of the pores as diffusion barrier for the gas phase educt species}

Gas phase impregnation (i.e. CVD on the inner surface of pores in porous substrates) is of great industrial importance. It started in the sixties with the fabrication of carbon/carbon composites by building up the carbon matrix via CVD. It is today more important because of the infiltration of carbon/carbon composites with silicon carbide as protection against high temperature oxidation. 
(a)

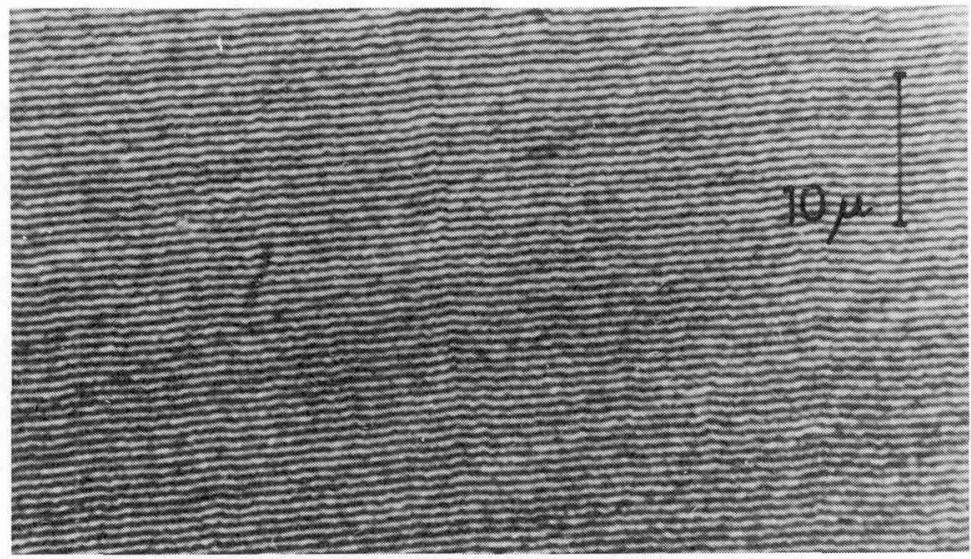

(b)

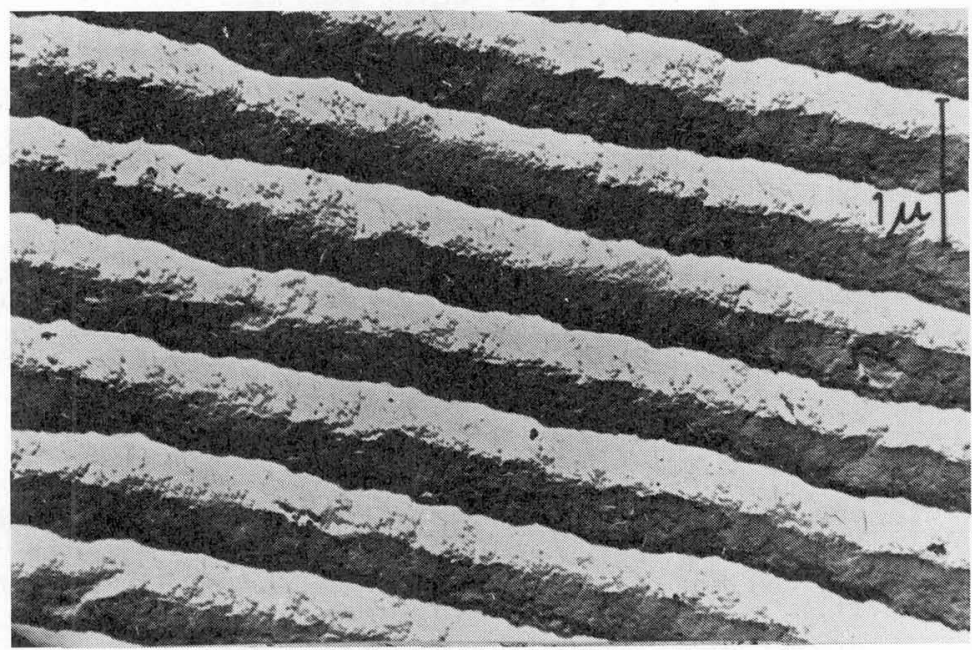

Fig. $9 a, b$ : SiC deposits with $12 \%$ free carbon

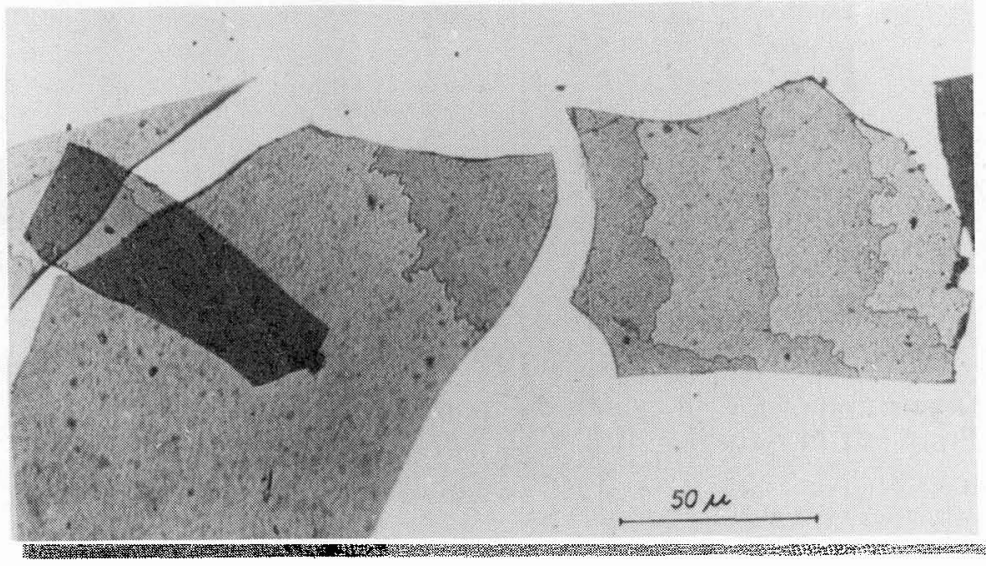

Fig. 10: Delamellation after impact 

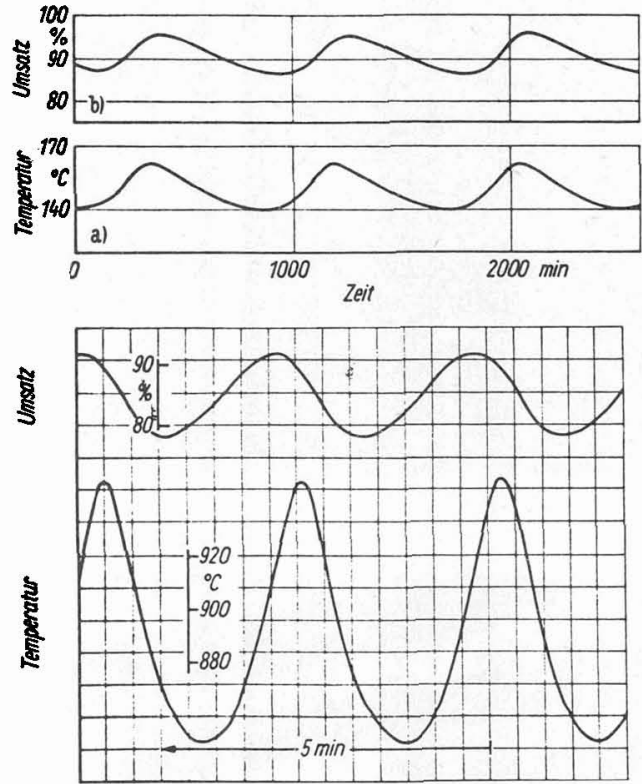

Fig. 11: Examples of oscillating chemical reactions. Top: polymerisation in a technical back mix reactor. Bottom: $\mathrm{N}_{2} \mathrm{O}$ decomposition in a tubular laboratory reactor with partial feed of product to the reactor entrance
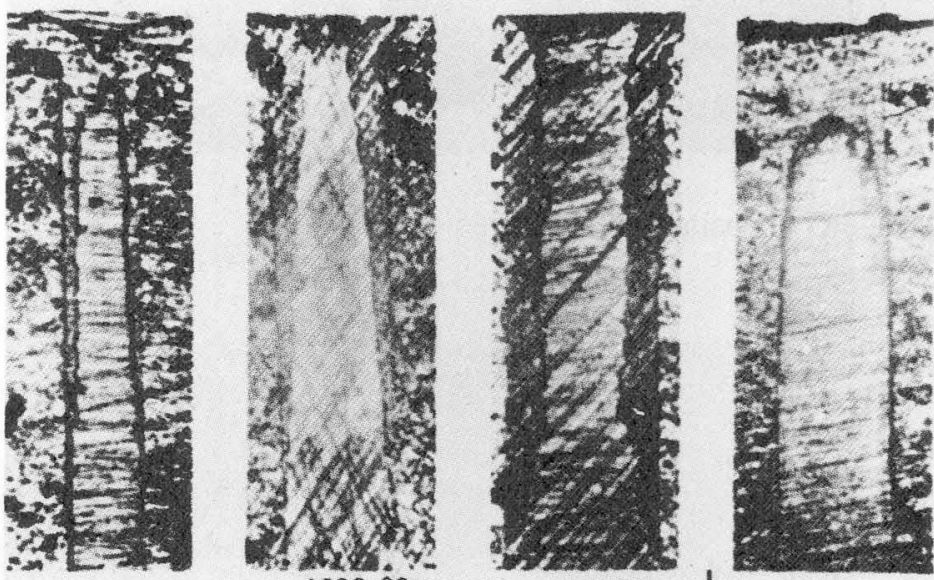

$500 \mu \mathrm{m}$

$1500^{\circ} \mathrm{C}$

Fig. 12: Deposition of $\mathrm{SiC}$ in cylindrical model pores in graphite. From left to right $d=400,600,800,600 \mu \mathrm{m}$ 
A similar problem is well understood in reaction engineering for heterogeneous gas/solid catalysis, and the calculation of the effective efficiency of the pores as solid catalysts for the reaction occurring in the pores. In order to guarantee homogeneous deposition of layers within the pores, the deposition reaction should not be controlled by the diffusion rate of the gaseous species in the pores, but only by the reaction rate on the inner surfaces; that means the CVD process has to be performed under reaction parameters such as low pressure and low temperature. Otherwise, the deposition will take place in the pore areas near the outer surface of the substrate and will lead to the formation of closed pores. That means impermeable pores, as demonstrated experimentally. Fig. 12 shows micrographs of model pores in synthetic graphite impregnated with $\mathrm{SiC}$ under various conditions. One can recognize the above mentioned effect (13).

Quantitative considerations of such heterogeneous reactions can be performed by means of dimensionless numbers. The Damkoehler number $\mathrm{Da} \Pi \mathrm{II}=\mathrm{k} \cdot \mathrm{L}^{2} / \mathrm{D}$ or the Thiele modulus $\left(\varnothing=\left(\mathrm{Da}_{\Pi I}\right)^{1 / 2}\right)$ can be used respectively. Both numbers describe the ratio between the rate of the chemical reaction and of the gas diffusion. Using the mathematical solution of the effectiveness factor $\left(\eta=\tanh \left(\mathrm{Da}_{\Pi I}\right)^{1 / 2} /\left(\mathrm{Da}_{\Pi 1}\right)^{1 / 2}\right)$ in heterogeneous gas catalysis (14) and kinetic data for the reaction and for the diffusion rate, $\left(\mathrm{Da}_{I I}\right) 1 / 2$ values will be

\begin{tabular}{lllllll}
\hline$\eta$ & 1 & 0.96 & 0.8 & 0.7 & 0.5 & 0.2 \\
$\left(\mathrm{Da}_{\mathrm{II}}\right)^{1 / 2}$ & 0.2 & 0.4 & 0.9 & 1.2 & 2 & 5
\end{tabular}

Let us assume an effectiveness of $96 \%$ (i.e. control of the rate of the overall deposition process by the rate of the first order chemical reaction), then under the precondition of cyilindrical pores, the mean length of the pores $\mathrm{L}$ will be

$$
\mathrm{L}=0.4 /\left(2 \mathrm{k}_{\mathrm{o}} / \mathrm{rD}\right)^{1 / 2}
$$

where $r$ is the radius of the pores (15).

The kinetic data for the SiC deposition were taken from (16a). The pore length $\mathrm{L}$ calculated in this way is shown in Fig. 13 for $\mathrm{SiC}$ deposition with a rate control by the chemical reaction rate as a function of deposition temperature for various pore diameters between 1 and $20 \mu \mathrm{m}$. These estimated pore length values for controlled inpore surface reaction are valid only for pore diameters remaining unchanged during the total deposition time and the assumption of cylindrical pores (Fig. 13b). Experimental data are also shown in Fig. 13b. The substrate was porous graphite with the pore size distribution as shown in Fig. 13a. The dotted line in (b) gives the experimentally measured depth of impregnation by $\mathrm{SiC}$; i.e. pore filling.

We can explain the difference between the course of the dotted and full lines by the diminution of the pore sizes as assumed from $20 \mu \mathrm{m}$ to less than $1 \mu \mathrm{m}$. As a first rough estimation, however, the calculated values are in good agreement with the experimental result. More detailed modelling calculations based on new improved kinetic data for the $\mathrm{SiC}$ deposition from methyltrichlorosilane have been performed by Schoch (16b) and will be presented in a separate contribution during this meeting. This more sophisticated model takes into account the pore size diminution during infiltration. Based on this model, we can precalculate the pore filling degree in various substrates after various CVI times, not only in porous solids, but also in sheets of whiskers or fibres, felts or textiles.

Fig. 14a shows the good agreement between experimental results for the layer thickness in model pores of $1000 \mu \mathrm{m}$ initial diameter (symbols) and precalculated values (full line) as a function of the distance from the pore entrance. Fig.14b gives some results on $\mathrm{SiC} \mathrm{CVI} \mathrm{in} \mathrm{sheets} \mathrm{made} \mathrm{of} \mathrm{SiC}$ whiskers. In this case, the CVI effect is expressed as closed porosity after various impregnation times for deposition temperatures of 900 and $1000^{\circ} \mathrm{C}$ and various total pressures. In agreement with the model, closed porosity is always formed. Again, the model calculation is shown as curves and the experimental data as symbols (16b). The good agreement within a few per cent demonstrates the applicability of the model even in cases of substrates with an original porosity of about $90 \%$ and a very broad distribution of pore radii.

\subsection{CVD coatings on monofilaments within a fibre bundle}

CVD is the only possible method for depositing layers of high melting metals or compounds on carbon fibres, which is of interest in composite technology or for superconducting films, as reported later. We started with this technique already in the early seventies $(15,17-21)$. 


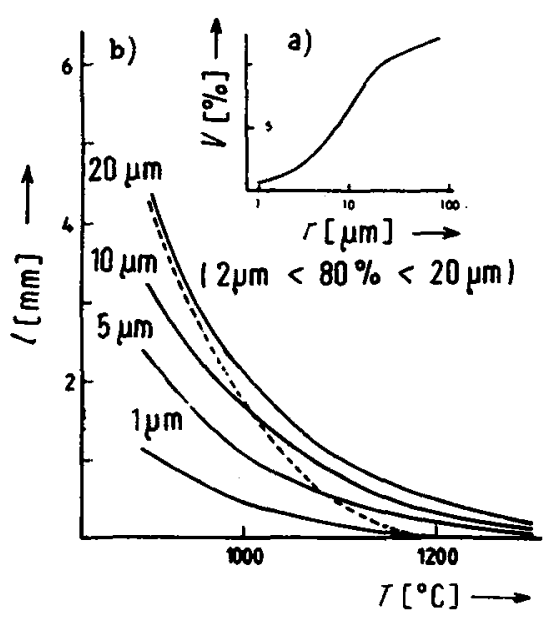

Fig. 13: Pore size distribution of porous graphite (a) Pore volume (V) vs pore radius (r) (b) Depth of impregnation in porous graphite vs temperature.

calculated for cylindrical pores

------ experimental

Pore radius is given next to the curves. Impregnation was with $\mathrm{CH}_{3} \mathrm{SiCl}_{3}$

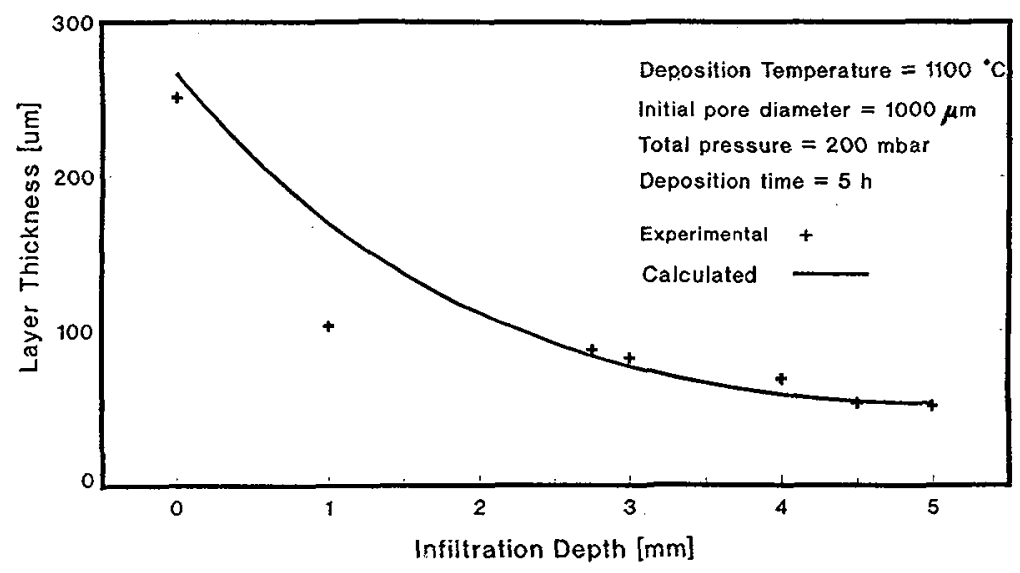

Fig. 14a: Thickness of SiC-layers calculated according to the model (full line) and measured for examples with model pores of $1000 \mu \mathrm{m}$ initial diameter (symbols) 


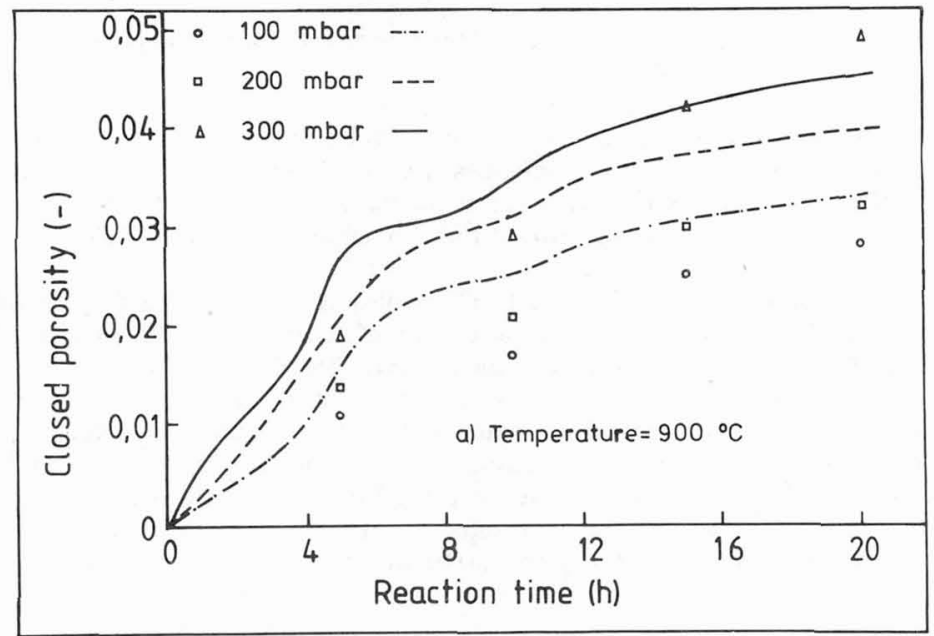

Fig. 14b: Closed porosity of a SiC whisker sheet, calculated according to the model for various pressures (curves) and measured on SiC CVI experiments

Fig. 15: trom $\mathrm{CH}_{4}$ and $\mathrm{TiCl}_{4}$ at

$1300^{\circ} \mathrm{C}$

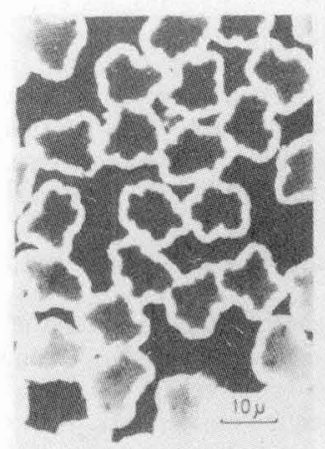

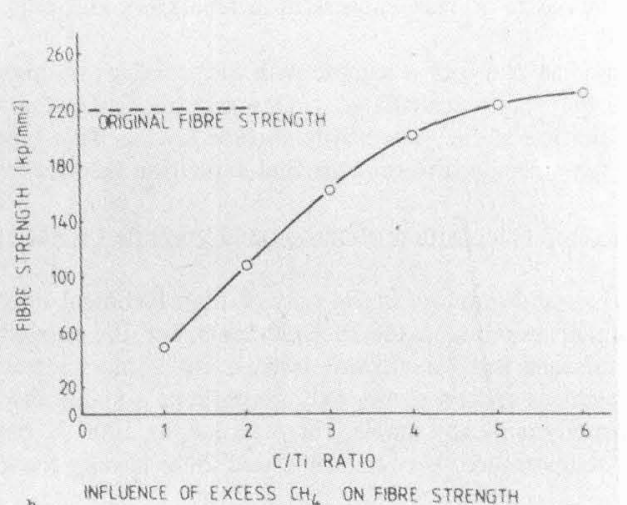


Fig. 15 shows such relatively thick coatings of titanium carbide on the formerly commercially available rayon based carbon fibres type Thornel. Titanium carbide is a very interesting case because of its broad area of homogenity; i.e. solubility for titanium and for carbon. It has been found that excess carbon is needed to form such titanium carbide layers. Otherwise carbon will be dissolved from the carbon fibre substrate and the fibre monofilament strength is reduced. The thickness of the coating is also of great importance because it strongly influences the fracture behaviour, and,in general, thick coatings are less favourable.

The carbon fibre bundles consisted at that time of some hundred monofilaments, but we have now at least 3000 monofilaments. The equipment developed in the seventies is shown in Fig. 16. The principle of our equipment with the continuously moving fibre substrate has been followed in all further developments, even in industrial laboratories (22). Also in the former GDR such equipment as described by us in literature was copied (23).

The kinetic problem in handling this process consists of avoiding the preferred surface deposition on the fibre bundle which would inhibit CVD of coatings on the surface of the monofilaments within the bundle. In principle it is the same problem as for CVD infiltration which has been discussed above. The deposition rate must be controlled by the rate of the chemical reaction on the surface, but not by the rate of diffusion of the species of the educt into the bundle. Also for this purpose a model and precalculation of the reaction parameters based on the known chemical kinetics has been developed (24). The basis of this model is a description of the fibre bundle as shown in Fig. 17. Additionally, the decrease of concentration of the educt species in the gas phase has been considered because of the hot wall arrangement and partial SiC-deposition on the inner wall of the reactor as indicated in Fig. 18. The mean coating thickness $\left(\mathrm{h}_{\mathbf{i}}\right)$ on the monofilament, deposited during the reaction time, can be written as

$\bar{h}_{i}=k \cdot n \cdot\left(x_{i}^{e i n}-x_{i G l}\right) \cdot \frac{M_{i}}{\rho_{i}} \cdot \tau$

where

$\mathbf{k}$
$\mathbf{n}$
$\mathrm{x}_{\mathrm{i}}{ }^{\mathrm{ein}}, \mathrm{x}_{\mathrm{i}, \mathrm{Gl}}$
$\mathrm{M}_{\mathbf{i}} / \rho_{\mathrm{i}}$
$\boldsymbol{\tau}_{\mathrm{L}}^{\mathrm{L}}$
$\mathrm{W}_{\mathrm{F}}$

$=$ reaction rate constant

- molar amount of the solid product

- molar content of the educt in the feed and in equilibrium respectively

= conversion factor of the solid product into the layer thickness

$=\quad$ residence time of the fibre in the tubular reactor $\left(=\mathrm{L} / \mathrm{W}_{\mathrm{F}}\right)$

- length of the reaction zone

- transport velocity of the fibre bundle

This model has proved to be very successful in laboratory and pilot experiments.

Fig. 19 shows an SEM photo of a sample with SiC coatings on high modulus carbon fibres as substrate, for which a layer thickness of $650 \mathrm{~nm}$ was precalculated. One may recognize that cutting of the fibres for sample preparation causes in many cases a spallation of the very brittle surface layers. This type of damage occurs also very often because of physical incompatibility (e.g. strongly different thermal expansion behaviour of substrate and coating).

\section{Chemical vapour deposition of carbon and graphite - a variety of problems due to anisotropy and crystalline order}

The CVD of carbon and graphite is not only of high technical importance for the fabrication of pyrolytic graphite and of coatings on granular uranium oxide fuel elements, for the production of carbon/carbon composites as nozzles for solid fuel engines in missiles and for aircraft brakes, but is most attractive for scientific research. As is known, the phase diagram of the element carbon shows only graphite as a stable modification up to pressures above thousands of kilo bars. Diamond is thermodynamically stable, for instance, at $1000 \mathrm{~K}$ only above $30 \mathrm{kbars}$. For CVD of carbon from volatile hydrocarbons at temperatures between 1400 and $2800 \mathrm{k}$, only the graphite modification is to be expected.

This section will report unusual observations on graphite crystal growth starting from dislocations in the substrate, catalytic influence on the morphology and finally the unexpected vapour deposition of diamond at low pressures.

\subsection{Spiral growth of pyrolytic carbon - the importance of dislocations as nuclei in the substrate}

Because of the high anisotropy of the graphite lattice and the binding conditions within the layers, crystal growth will preferably proceed in a direction parallel to the layers. From thermodynamic considerations of stability of hydrocarbon compounds it is known that low molecular aromatic species are preferred with increasing temperature as compared with aliphatic ones. In competition to the above mentioned growth of the individual layers the aromatic species tend to form staples. These staples formed during pyrolysis are microcrystalline but disordered in the c-direction. 


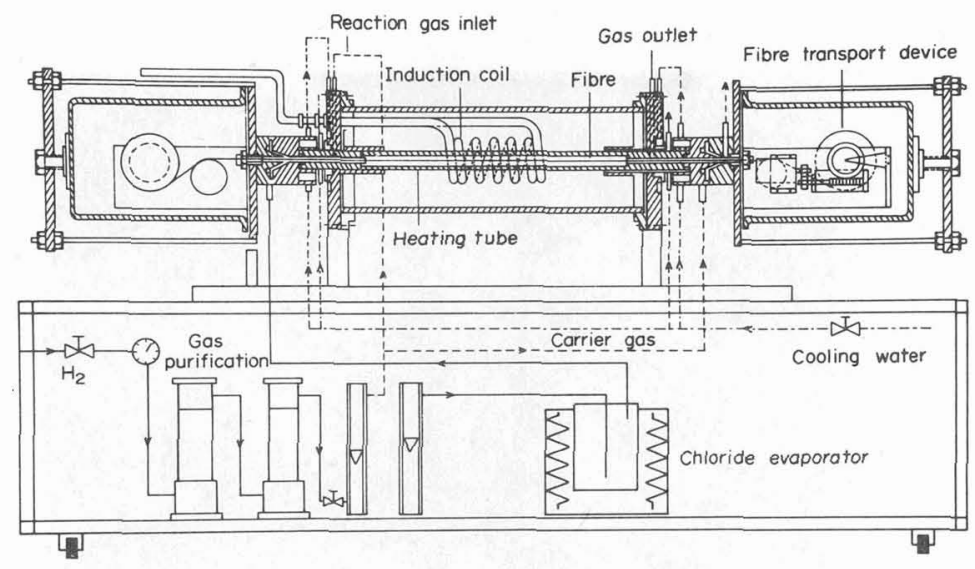

Fig. 16: Laboratory equipment for continuous CVD on monofilaments in a fibre bundle

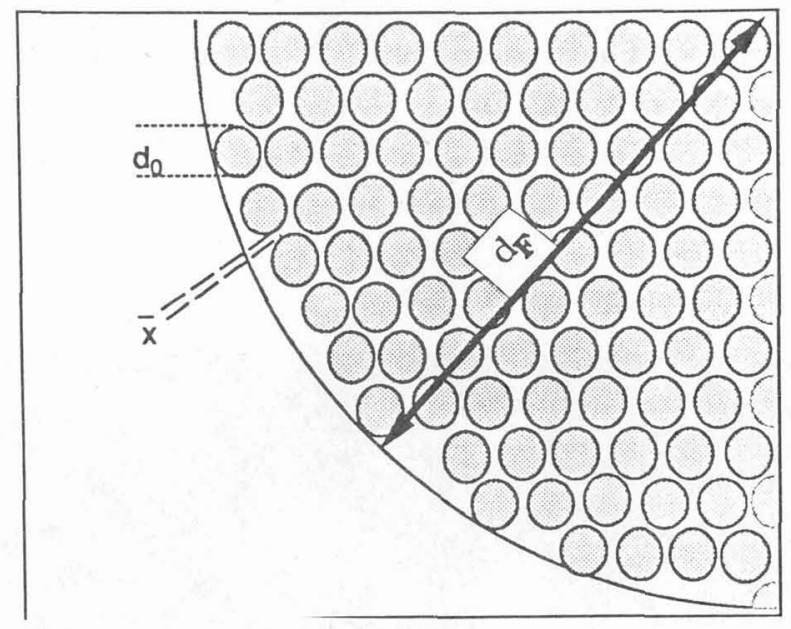

Fig. 17: Description of the fibre bundle in the model

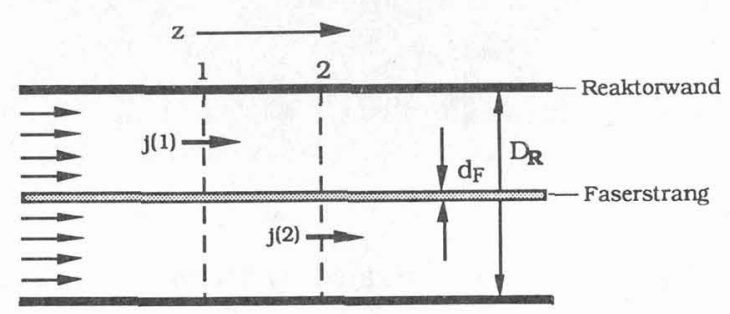

Fig. 18: Explanation of the modelling of CVD fibre coating in a tubular hot wall reactor 


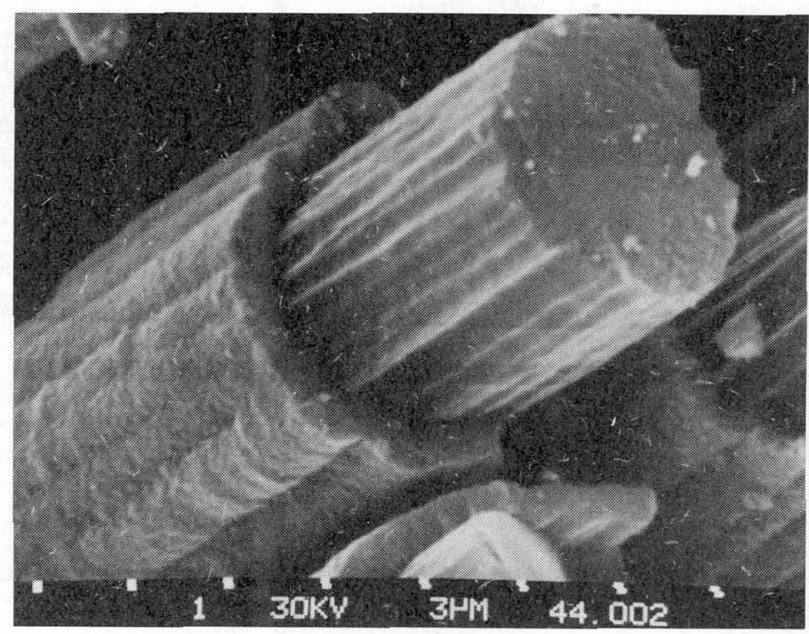

Fig. 19: SEM of HM carbon fibres, coated by CVD with relatively thick SiC layers

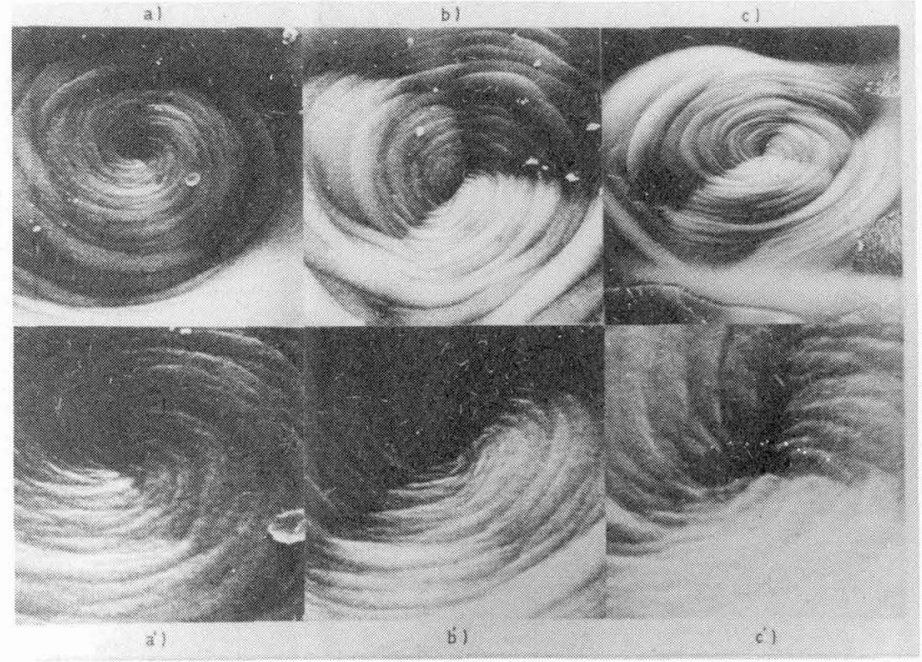

Fig. 20: Surface of spiral pyrocarbon initiated by screw dislocations in the surface of the substrate (29) 
These tendencies in crystal growth cause a plurality of structural phenomena in pyrocarbon deposits. At low temperatures of about $1000 \mathrm{~K}$ mainly a lower morphology is found because of the polyaromatic intermediates formed as spherical liquid crystals. At higher temperatures the deposition is initiated by nuclei at the surface of the substrate. This leads to crystals growing as cones. Such nuclei found in the surface of the substrates lead to the so-called surface nucleated pyrocarbon, whereas nuclei formed already within the gas phase, mainly in case of high supersaturation, lead to the so-called gas phase nucleated structures. Many years ago we already observed spiral growth of pyrolytic carbon in reproducible experiments carried out by various co-workers (25-28). Fig. 20 gives an idea of the surface structure of layers grown as spirals. Spiral growth of crystals is well known to be initiated by screw dislocations in the surface of the substrate. As shown in Fig. 21 one can distinguish the surface morphology arising from point, line and threefold surface defects. Furthermore, one can find twin spirals as shown in Fig. 21a and a spiral with inverse rotation direction (Fig. 21b), explained by the so-called Frank-Reed source. All these types are explicable by the well known growth mechanism initiated by dislocations in the surface (29).

Most surprising is the height of the growth steps of the spirals of the order of ten thousands of nanometers. This means that spiral growth is a cooperative process occurring simultaneously in thousands of aromatic layers. Although scientifically very interesting, the spiral growth has not yet been discussed on the basis of sophisticated considerations.

Fig. 22 shows a cross section of such a spiral growth which is really exceptionally interesting. One can recognize the surface initiated crystal growth with increasing spiral diameters up to $150 \mu \mathrm{m}$ and then a regularly pyrolytic carbon growth in the form of columnar crystals. It may be mentioned that this pyrolytic carbon had a good structural preorientation resulting in perfect structure after graphitization heat treatment at about $3000 \mathrm{~K}$.

\subsection{Whisker growth of pyrolytic carbon - the influence of solid catalysts on the morphology of deposits}

On occasions when spiral growth in a tubular hot wall arrangement has been observed, whisker growth has also been observed. Whisker growth is surface nucleated too, in this case in a tube of commercially available artificial graphite (26).

Fig. 23 gives an idea where whisker growth and where spiral growth have been observed. Whisker growth occurs at high supersaturation in the gas phase and relatively low temperatures; i.e. near the entrance of the heated tube. Spiral growth was observed in the middle of the tube at higher deposition temperatures; i.e. in a region where the concentration of the educts in the gas stream has decreased because of the depotion in the preheated zone or by some cracking reactions forming soot which is transported through the tube and deposited only at the end of the tube.

The kinetics of the whisker growth has been observed directly by a telescope. As shown in Fig. 24 it starts with a very fast growth lengthwise, and after some seconds the growth of the deposit is mainly a growth laterally of the whisker, forming needles.

We have to distinguish two mechanisms. The first step is a catalytic growth initiated by iron or other metal impurities in the surface of the artificial graphite acting as nuclei. The whisker growth occurs through the solid catalyst; i.e the catalyst shifts always to the head of the whisker, while carbon deposits are dissolved in the catalyst and precipitated on the other side of the catalyst as very perfect pyrolytic graphite. This catalytic growth is described very comprehensively elsewhere. In today's literature such whiskers are called "filamentous" carbon (30).

The second step is the lateral growth, a process similar to that of conventional pyrolytic carbon deposition on the substrate. Because of the geometry of the substrate and the above mentioned tendency of preferred layer growth of the deposits, a carpet rolling mechanism can be observed during this second growth phase of pyrolytic carbon on the primary whiskers. In some cases a screw like growth mechanism in the surface, as indicated in Fig. 25a, was observed.

Already in the seventies we measured the strength of such whiskers and needles. Mechanical values of $1400 \mathrm{MPa}$ for strength and $30 \mathrm{GPa}$ for modulus have been found (see Fig. 26). Today, such filamentous carbon is produced in pilot scale plant by seeding of fine grain catalyst on the substrates. Similar mechanical properties are reported (30). Filamentous carbon can become technically important because it is one of the less expensive sources for carbon in the form of fibres or filaments for possible reinforcement purposes.

We also tried to measure the strength of the spirally grown pyrolytic carbon, although it is very difficult to prepare samples for such measurements. Nevertheless, in Fig. 26 the data published at that time are presented and shows that the spirally grown carbon has much less structural defects and therefore higher strength than the conventional pyrolytic carbon. 

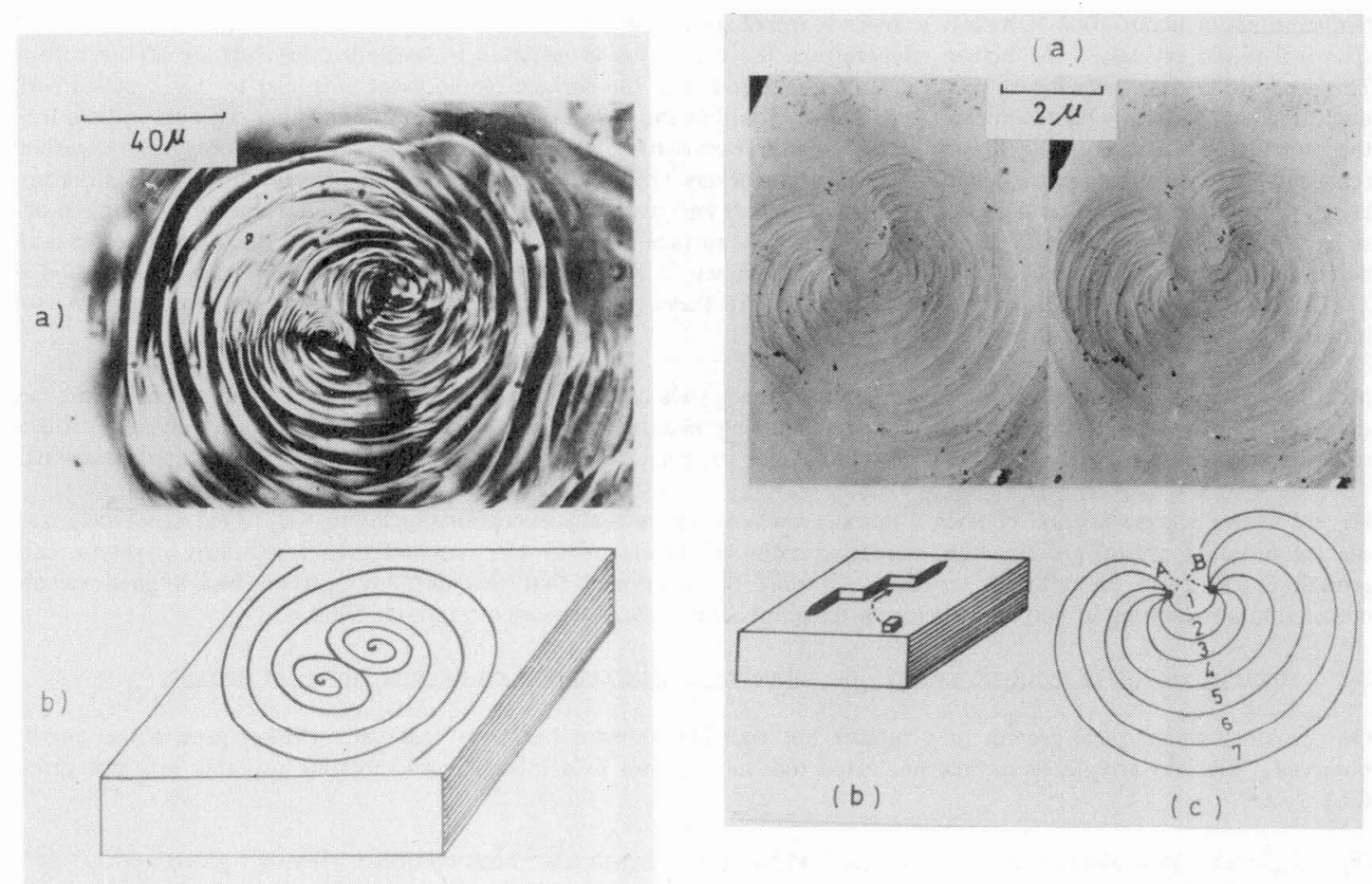

Fig. 21: PC-spiral - left side: Twin spiral a: surface view right side: Frank Read $\begin{gathered}\text { schematically } \\ \text { spiral growth }\end{gathered}$

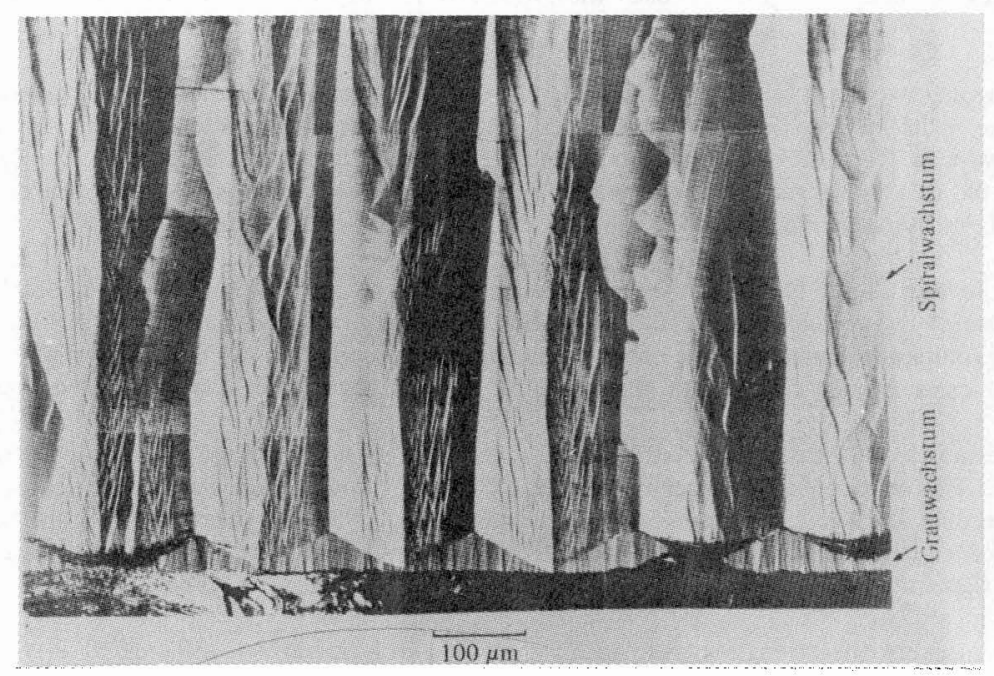

Fig. 22: Cross section of a spirally grown pyrocarbon layer 

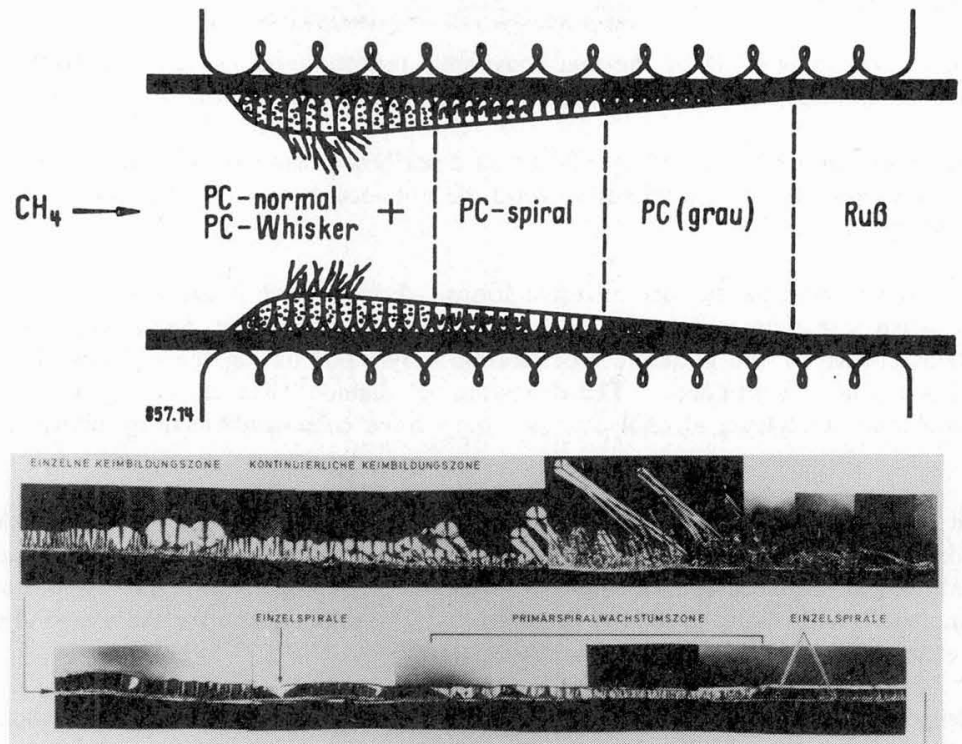

Fig. 23: Place of whisker growth during deposition in a tubular hot wall reactor Top: $\quad$ schematic (gas entrance from left)

Bottom: micrographs (gas entrance from right)

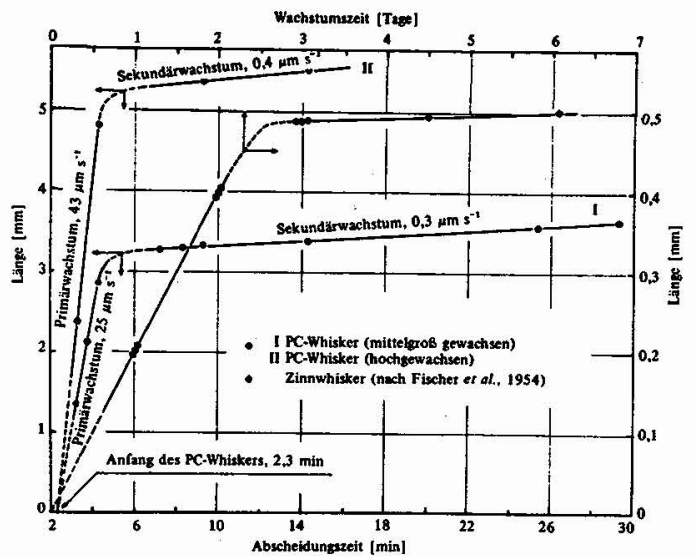

Fig. 24: Growth of PC whiskers 
3.3 Diamonds by CVD at low pressures - unexpected because of thermodynamic instability but explained by rehydrogenation of aromatic and oraphitic deposits by atomic hydrogen

We all are used to explaining CVD by the thermodynamic preconditons; i.e. the stability limits of volatized compounds and their thermal decomposition or chemical reaction with other gaseous species or with the substrate.

In the fifties, the formation of diamond by CVD was described already in the patent literature (31) and in 1969 in a scientific publication (32). The whole scientific world did not accept these observations, and neither did we, because it is thermodynamically not acceptable.

Disordered solid carbon can exist in very different forms. For instance it can also exist in the form of extremely hard glassy carbon. Most scientists and we too (33) have tried to demonstrate that in spite of the extreme hardness such disordered carbons consist of the graphitic modification only. But during the eighties, the observations on disordered diamond like deposits have multiplied. The deposition of diamond like carbon layers by CVD and also of diamond crystals using methane, acetylene, alcohol etc. as educts have been confirmed by many scientists all over the world $(34,35)$.

Today we know, that this surprsing low pressure diamond formation is explicable only by kinetic effects. It has been mentioned before that the thermodynamic stability of aliphatic species in the gas phase is lower with increasing temperature than that of aromatic ones. Aliphatic hyrocarbon compounds have $\mathrm{sp}^{3}$ hybridization which causes isotropic interatomic homopolar bonds with tetrahedral orientation. The same is true for the diamond modification of carbon. It is the classical example of $\mathrm{sp}^{3}$-hybridization in carbon atoms.

In aromatic compounds, the $\mathrm{sp}^{2}$-hybridization, the same as in graphite, causes only 3 homopolar bonds in a planar arrangement, whereas the 4th binding electron of carbon is acting perpendicular to the plane forming a very weak chemical bond of metallic character. It must be mentioned again that the aromatic modification in carbon/hydrogen compounds is combined with a maximum $\mathrm{C} / \mathrm{H}$ ratio of 1-1 in the case of benzene, but with much lower hydrogen content in polyaromatics. On the other hand, the aliphatic arrangement has higher hydrogen contents up to $1: 4$ in the smallest paraffinic molecule methane. During thermal decomposition the chemical mechanism of dehydrogenation is known to be very complex, including the formation of free radicals such as methyl and others. Depending on the temperature gradient and supersaturation of the educt in the gas phase, various combinations of aliphatic and aromatic constituents form the first solid depsoit. Some percent of hydrogen is present not only in the gas phase but also in the deposits. On the hot surface rehydrogenation can occur in competition with the thermal dehydrogenation. Due to the different reaction rates aromatic deposits react much faster with active hydrogen than the aliphatic ones. One speaks of the solubility of carbon in an active hydrogen atmosphere; i.e. re-volatilization of the deposit.

Further splitting off of the hydrogen in $\mathbf{s p}^{3}$-deposits can lead to the diamond structure if diamond nuclei are present. According to our literature information such diamond nuclei always seem to be needed. Thus, the probability of crystal growth from the aliphatic deposits with low hdyrogen content is very high in active hydrogen because of rehydrogenation of the aromatic carbon deposits. It is reported that diamond deposition occurs in the temperature range below $1300 \mathrm{~K}$ at a total pressure between 5 and 50 torr. Such deposits in active hydrogen can exhibit film or crystal structure. Crystal morphology always shows a diamond structure, whereas the film morphology is mainly composed of disordered carbon and sometimes diamond as confirmed by solid laser Raman spectroscopy (36).

Diamond is well known for its extremely high heat conductivity and if it is possible to form controlled layer growth, it could be applied for cooling devices in computer technology on the rear of silicon chips.

\section{CVD of superconducting surface layers - deposition of compounds with four components and controlled crystal structure}

In the late seventies we tried to deposit superconductors based on niobium carbonitride with a transition temperature around $18 \mathrm{~K}$. In the late eighties we made the same efforts with high temperature oxidic superconductors of the type yttrium- barium- copper oxide $\mathrm{YBa}_{2} \mathrm{Cu}_{3}{ }^{0} 7-\mathrm{x}$.

\subsection{Niobium carbonitride deposits on carbon fibres}

Among the superconducting compounds, niobium carbonitride has the advantage of a relatively high transition temperature within the family of the classical low temperature superconductors. Due to its micrstructure it has also the capacity for high current density at high critical magnetic fields. Problems due to brittleness could be overcome by use of film geometry. The phase diagram of niobium/nitrogen and with carbon addition is shown in Fig. 27. The 


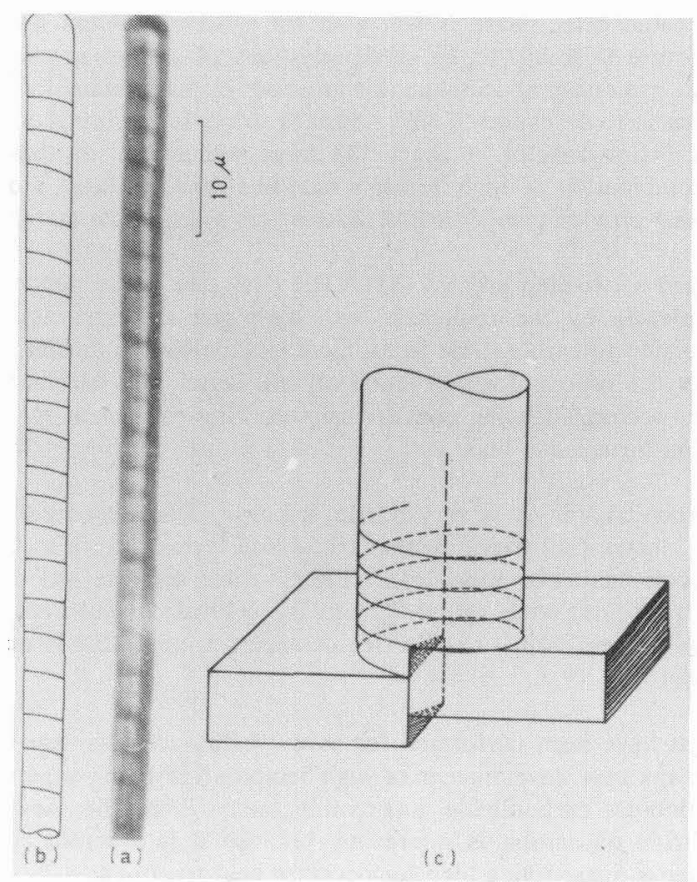

Fig. 25: PC whisker - a) photograph

b) schematic

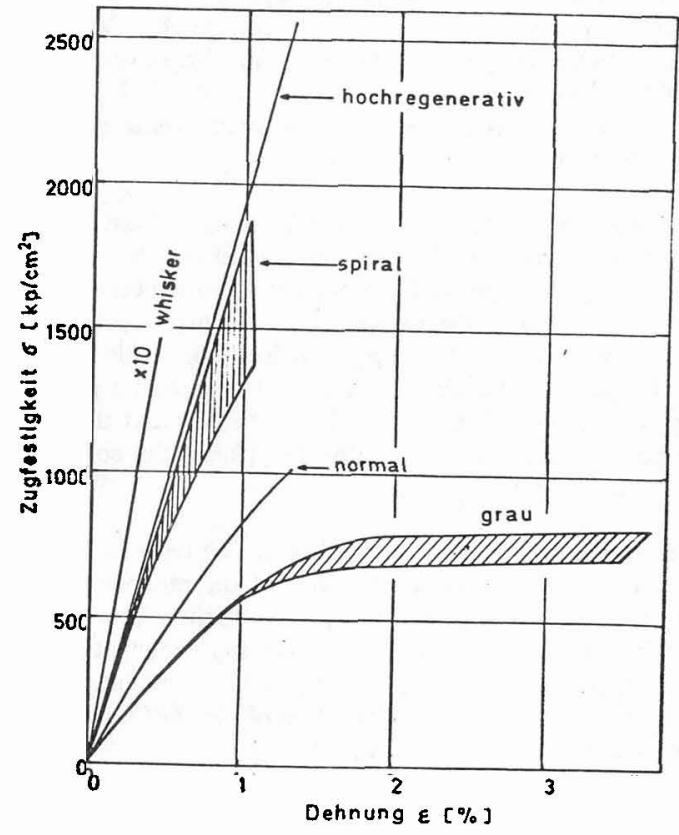

Fig. 26: Mechanical properties of PC, deposited in a hot wall tubular reactor as published by us in 1972 
superconducting cubic delta phase is stable in the system niobium and nitrogen only at temperatures above $1250^{\circ} \mathrm{C}$, whereas the structure is stabilized by small additions of carbon as can be seen from part (b) in Fig. 27. Due to the simple B1 crystal structure of niobium nitride and its understoichiometric composition only a slight degradation by neutron irradiation is to be expected (37). This property is advantageous for the application for the plasma containment of the Tokomak fusion reactor. Since the large dimensions of these magnets imply strong tensile stresses in the conductor, the combination of high Young's modulus carbon fibres, providing the mechanical stability, with a niobium carbonitride coating providing superconductivity offers a candidate material to fit these requirements.

We have developed a two-step process (38). The first step is the deposition of elemental niobium or of niobium nitride from niobium chloride by the reduction with hydrogen at temperatures of about $1000^{\circ} \mathrm{C}$. The second step is the subsequent conversion to carbonitride in an ammonia/methane atmosphere at temperatures of about $1100^{\circ} \mathrm{C}$ (see fig. 28 , route 3). As for the process for deposition of thin layers in a carbon fibre bundle developed in our institute, all these experiments were performed using continuously working equipment (see Fig. 29). The only variation consists of two separate deposition furnaces in line.

Although the carbonitride layer is very brittle, the experiments succeeded in forming layers with sufficient adhesion (see Fig. 30). In the most recent experiments carbon interlayers have also been used, produced by vapour deposition. For this a 3-step process has to be done (24). Fig. 34 gives some results from the early work on this subject, expressed as the critical (i.e. transition) temperature $T_{c}$ and the critical current density, plotted as a function of the temperature for the carbonitration process step. Critical temperatures around $15.4 \mathrm{~K}$ and critical current densities up to $10^{5} \mathrm{Amp} / \mathrm{cm}^{2}$ have been achieved.

These experiments have been performed for some years and have also been used by industry for industrial applications (22). However, the new development of high temperature oxide superconductors after 1986 has reduced the technical importance of niobium carbonitride superconductors. From the viewpoint of the CVD-technique this work on the niobium carbonitride deposition is interesting because it is a multistep CVD-process, the second of which involves a secondary reaction and controlled high temperature heat treatment.

4.3 Deposition of oxide high temperature superconductors - the CVD of a ternary oxide with controlled stoichiometric composition and preferred orientation of the isotropic crystals

YBCO has become one of the technically most interesting oxide superconductors with critical temperatures of about $90 \mathrm{~K}$ and critical current densities up to $16^{6} \mathrm{~A} / \mathrm{cm}^{2}$, for PVD thin layers. The key to the deposition of oxide high temperatures superconductors is the simultaneous deposition of the elements yttrium, barium and copper as oxides in the ratio 1:2:3 from the respective evaporated educt compounds. Vapour deposition of these oxide forming elements is difficult and special complex compounds stable during evaporation are needed. Several chelate complexes are today commercially available as shown in Fig. 32. We have found that tetramethylheptanediones (thd) of all three metallic elements to be most suitable educt components. Recent studies performed by Schmaderer (39a), will be reported on in more detail in a separate lecture.

Fig. 33 shows the evaporation rate of these three chelates from which we can derive the composition of the vapour entering the reactor as a function of the temperatures in the three separate evaporators. It has been recognized that a correct composition of the educt gas yields a correct stoichiometry of the deposits. It has been recognized furthermore, that the continuous evaporation of the barium chelate causes most difficulties. In the case of barium deficiency in the vapour phase a barium deficiency in the deposits arises too. This leads to crystallization of non superconducting Ba free $(\mathrm{Y}, \mathrm{Cu}, \mathrm{O})$ crystals. To describe the stoichiometry of the deposit a paramter $\epsilon$ is used which gives the deviation from the correct composition $\mathrm{Y}=1, \mathrm{Ba}=2, \mathrm{Cu}=3$. It has been found that the $\mathrm{YBCO}$ phase is very stable and if there is any deviation from the correct stoichiometry of the gas. phase, the solid will be formed with complete consumption of the limiting component in the gas phase.

In our studies, in most cases, there was a lack of Ba activity. Therefore, the barium in the gas phase is completely consumed. In this case, $\epsilon$ is defined as the ratio of the number of metal atoms in the precipitates compared with the total number of metal atoms in the overall layer. As barium is in deficit as compared with the stoichiometry in the gas phase, it is completely consumed to form the stable superconducting 1-2-3 phase and the toal description of the layer with $\epsilon$ is given by $(1-\epsilon) /\left(\mathrm{YBa}_{2} \mathrm{Cu}_{3} \mathrm{O}_{7-\delta}\right)+\epsilon \mathrm{Cu}_{2} \mathrm{Y}_{\mathrm{x}} \mathrm{O}_{\mathrm{n}}$. This means that $\epsilon$ is the content of barium free precipitations distrubing the periodicy of the preferred orientation of the YBCO crystal structure layer and reducing the critical current density. Therefore, $\epsilon$ should be as small as possible.

Fig. 34 shows that the stoichiometry in the layer in some cases is not as precise as could be expected due to the precipitation of non conducting $B a$ free inclusions. Most important is obviously the correct preferred orientation which is maintained by using as substrate monocrystalline strontium titanate which has lattice parameters similar to those of the 

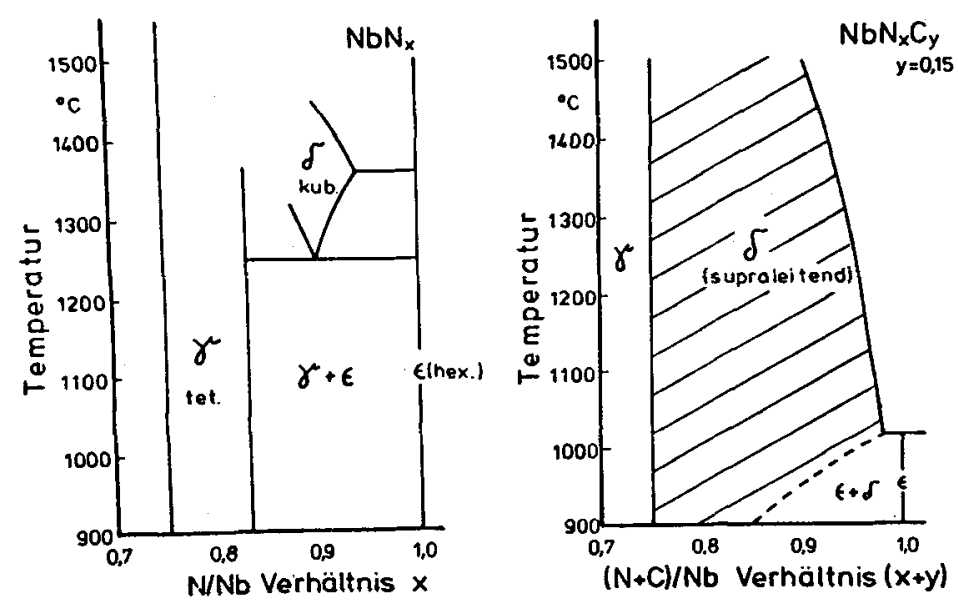

Fig. 27: Phase diagrams as the basis for $\mathrm{Nb}(\mathrm{C}, \mathrm{N})$ superconductors

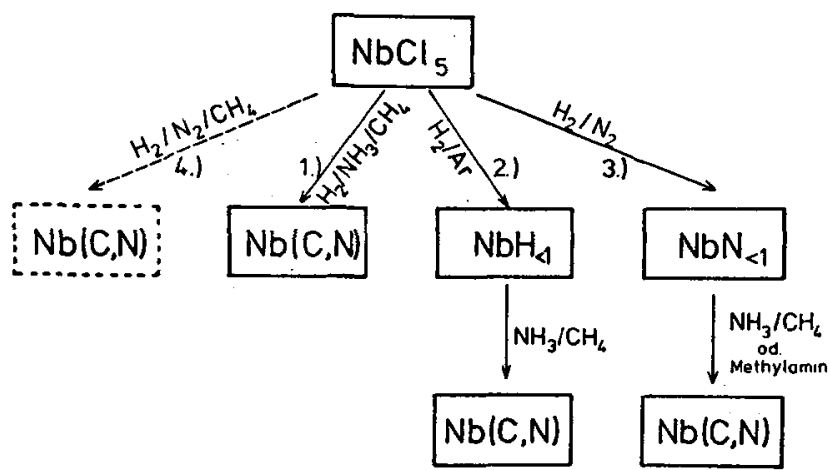

Fig. 28: Possible routes for CVD of $\mathrm{Nb}(\mathrm{C}, \mathrm{N})$ superconductors 


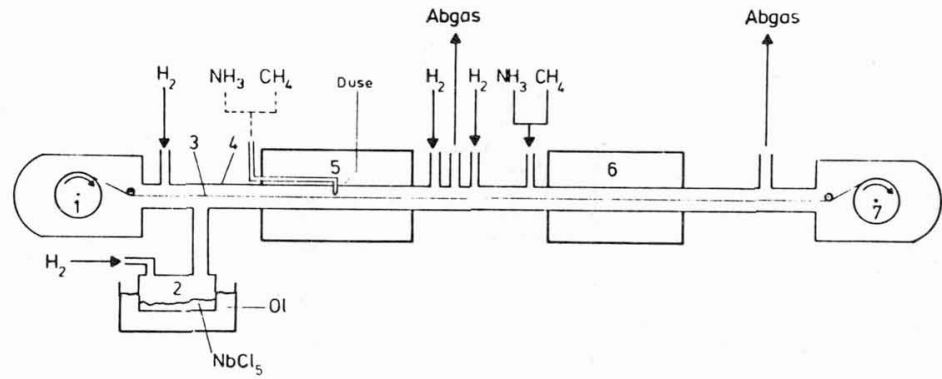

Fig. 29: Laboratory equipment for the two step-CVD of $\mathrm{Nb}(\mathrm{C}, \mathrm{N})$ superconductor 1 - bobbin for the substrate

2 - evaporator

3 - continuously moving C-fibre bundle

$4-\mathrm{SiO}_{2}$ tube

5 - reactor for $\mathrm{Nb}$-deposition

6 - reactor for carbonitration

7 - bobbin for the coated fibre bundle
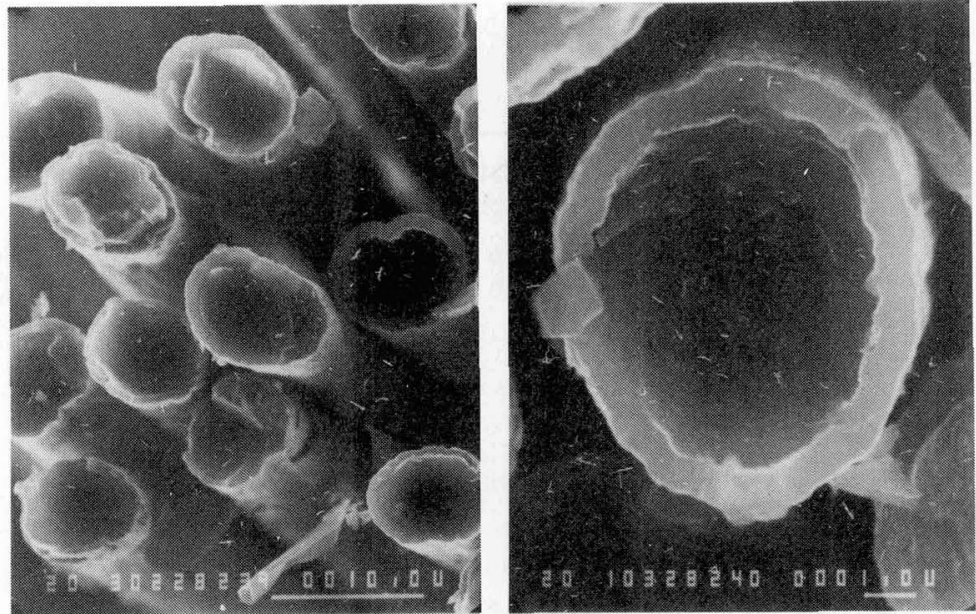

Fig. 30: $\quad N(B, N)$ layer with $W$ interlayer on carbon fibre monofilaments 


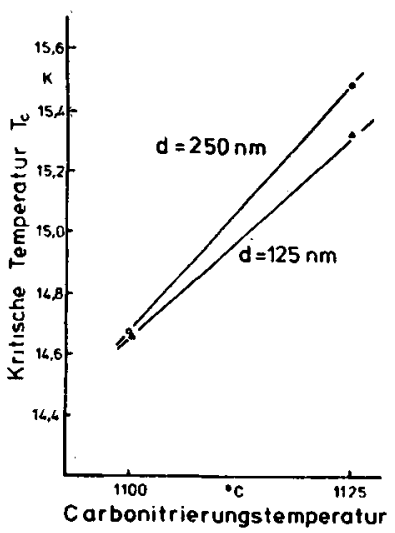

a)

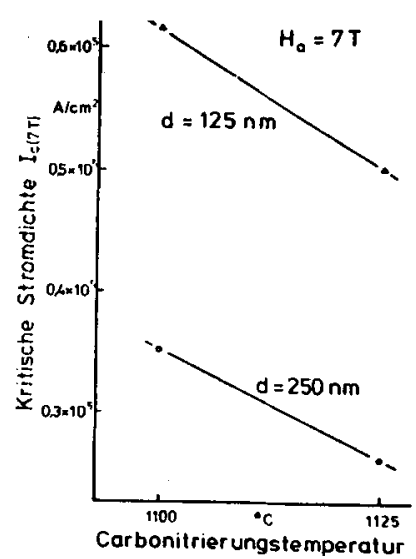

b)

Fig. 31: Critical temperature and critical current density of $\mathrm{Nb}(\mathrm{C}, \mathrm{N})$ coatings on carbon fibres as a function of the reaction temperature in the second tubular reactor

$$
\begin{array}{lll}
\text { Ligand } & \text { Aokurzung } \\
\text { Acetylaceton } & \text { (acac) } \\
\text { Hexafluoro- } \\
\text { acotylaceton }
\end{array}
$$

Fig. 32: Commercially available chelates of barium, yttrium and copper

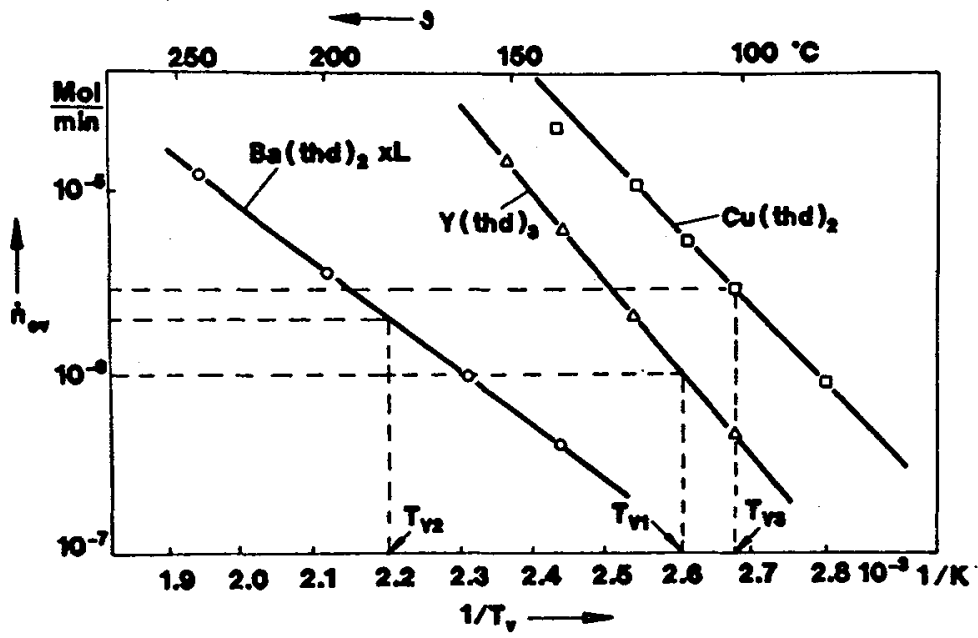

Fig. 33: Arrhenius plot for the evaporation of the chelates 

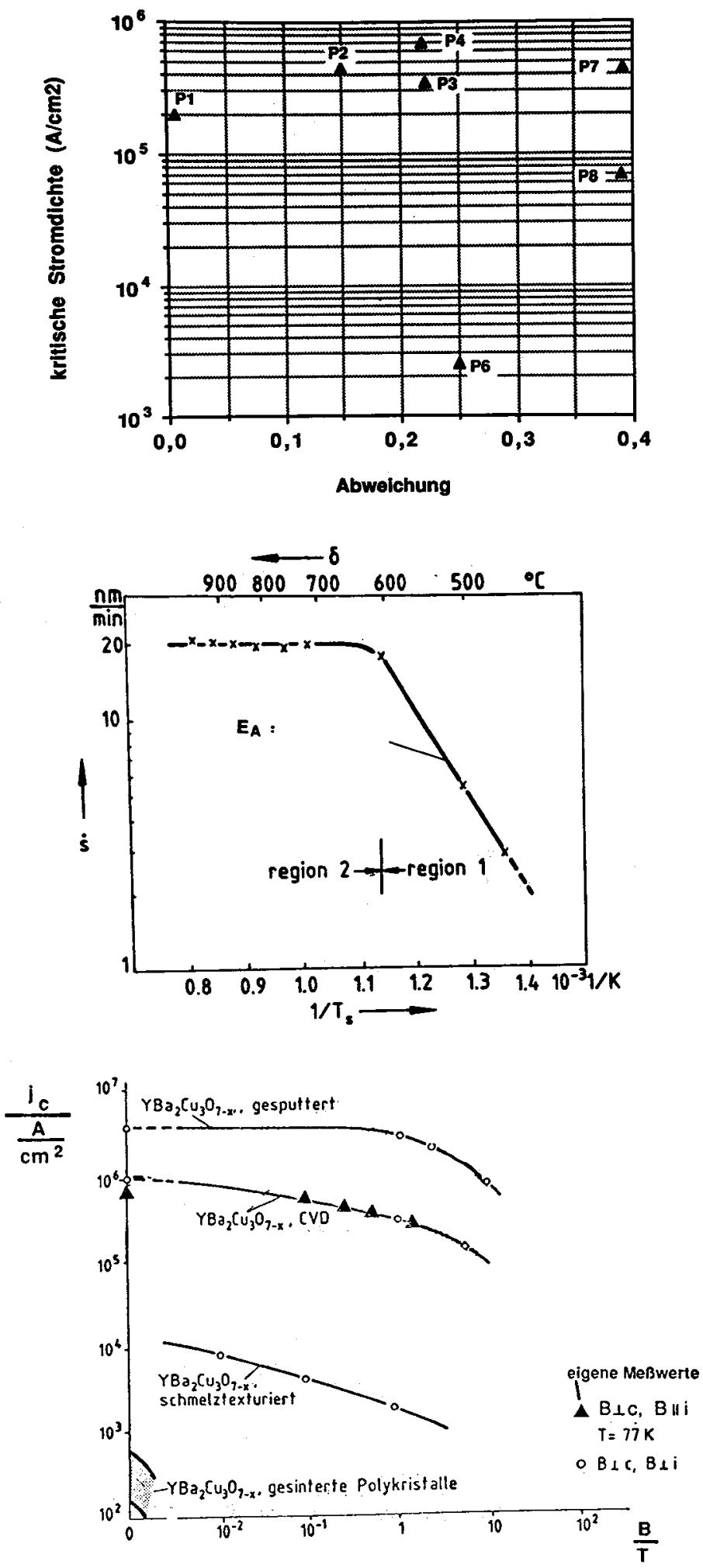

Fig 34:

Critical current density as influenced by the elemental composition of the substrate, expressed as a deviation

Fig. 35:

Arrhenius plot of the CVD-layer growth of YBCO superconductors

Fig. 36:

Critical current density in a magnetic field of CVD YBCO layers compared with PVD layers and sintered samples (according to G. Fitzer) (40) 


\section{YBCO phase.}

As far as the CVD kinetics on strontium titanate is concerned, Fig. 35 shows that the deposition rate becomes independent of deposition temperature above $600^{\circ} \mathrm{C}$. The composition of the deposit is therefore controlled through the gas boundary layer surrounding the substrate. One disadvantage of the process is the very low yield, typically below $1 \%$, which is needed in order to guarantee a variation of the composition of the back mixed volume in the flow reactor. It was found that this gas film can act as a regulator for equivalent diffusion of the species needed for deposition by thermal degradation.

Fig. 36 (40) demonstrates where the results of our research on YBCO by CVD can be placed within the known fabrication techniques for high temperature superconductors. The quality is nearly the same as that of the PVD layers. However, the CVD technique has the advantage of the possibility to produce thicker layers up to $1 \mu \mathrm{m}$ and more. High temperature superconduting oxides are commercially available today, but produced by a sintering technqiue which results in much lower current densities.

What is the conclusion from these studies on YBCO superconducting layers? Complex ternary oxides with defined stoichiometric composition and with well defined orientation can be made by CVD. The correct stoichiometry of the deposited layers can be achieved only when the CVD process is performed at temperatures at which the kinetics of the overall reaction is controlled by the rate of the diffusion through the surface layer. Furthermore, a stoichiometric composition of the gaseous educts leads to stoichiometric products. Further experience is that oxides can be deposited easily if the thermal decomposition is performed in an oxygen containing atmosphere because these elements have an extremely high affinity for oxygen. This secondary reaction of the decomposed species with oxygen occurs immediately at the surface of the substrate. There is confirmation that also in this case a controlled crystal growth can be obtained if a substrate with suitable nuclei is used. The further continuation of the development is exclusively in the hand of industry. As is known, industry will invest further development initiatives only if a broad and promising market can be found, which is not yet confirmed.

Further studies on oxide deposition in our institute are directed to fibre reinforced zirconia composites as heat barriers.

\section{Latest results on fibre reinforced oxide composites}

As is known, combustion engines should work at the highest temperatures which can be tolerated with regard to the metallic structural materials without a critical loss of mechanical properties. The strengths of all metallic high temperature materials used in combustion engines, the so-called superalloys fall below the minimum which can be tolerated in the engine at temperatures of about $1100^{\circ} \mathrm{C}$. Combustion temperatures in gas turbines need to be increased up to $1600^{\circ} \mathrm{C}$. There is thus a need to used oxide heat barriers between the burner gas and the metallic wall of the combustion chamber in order to realize these envisaged conditions.

Plasmas sprayed zirconia layers on nickel based alloys are the technical state of the art. There is a limitation to the application of this spraying method since only free surfaces can be covered and limited coating thicknesses are achievable because of mechanical stresses between the oxide with a thermal expansion of about $3.10^{-6} \mathrm{~K}^{-1}$ and a metal with a thermal expansion coefficient of about $12.10^{-6} \mathrm{~K}^{-1}$. The basic idea for new research in this area (41) is the fabrication of zirconia composites with commercially available zirconia fibres or textiles and a matrix made by CVD. As the heat barrier effect is best with a porous layer the matrix deposition can be limited to a minimum bulk density.

For deposition of zirconia the decomposition of zirconium chloride in a $\mathrm{CO}_{2} / \mathrm{H}_{2}$ atmosphere is used. The development in this work is far from complete and in particular the problem of adhesion of the oxide layer to the metallic substrate has not yet been satisfactorily solved. Furthermore, the oxide layers if very porous show a limited tolerance to reversible deformation at high temperatures or in a temperature gradient. For these porous layers as substrates short fibres of zirconia are used and the matrix is built up by the CVI technique. Theoretical considerations for selection of process parameters are being applied (16b).

\section{Conclusion}

It has been shown that the original purpose of CVD coatings on metals for fabrication of thin layers with special physical and chemical properties either by reaction with the substrate or diffusion into the substrate or by producing overlay coatings has been extended to the use of the CVD technique for pore filling of porous substrates or for building up of the matrix fibre reinforced composites. In order to evaluate the technical importance of CVD processes for coating purposes one has to consider two competing methods: for very thin layers physical vapour deposition and for thicker layers the vacuum spray technique. The first one has a limitation of layer thickness and also of very high costs. The second one can effectively compete with CVD application because it is the cheapest method to make overlay coatings. The 
limitation, though, is one of geometry, since one can deposit on free surfaces only.

It has been shown that CVD processes can not only supplement both these methods but also can offer a unique method for new high tech and highly sophisticated materials technology.

\section{Acknowledgements}

The author thanks all coworkers for their cooperation during the years, especially Dr. Schoch and $M$. Kiliani who were also a valuable help in preparing this manuscript.

Special thanks to Mrs. Philipp, who was engaged in typing of this camera-ready manuscript with an admirable enthusiasm even on Sundays and holidays.

\section{References}

1. Fitzer, E. Mikroskopie 6 (1951) 174

2. Fitzer, E. Archiv f.d. Eisenhuttenwesen, 25 (1954) 601

3. Fitzer, E. Archiv f.d. Eisenhuttenwesen 26 (1955) 159

4. Fitzer, E. Berg- und Huttenmannische Monatshefte 97 (1952) 81

5. Fitzer, E. Matthias, K. "Hochtemperatur-Werkstoffe", Proceedings 6th Plansee-Seminar (1968) 740

6. Brennfleck, K. Fitzer, E. Kehr, D. Proc. of 7th Intern. Conf. on CVD Los Angeles, Calif. (1979), 578

7. Kehr, D., PhD Thesis, University of Karlsruhe (1975)

8a. Fitzer, E. Schlichting, J. Proc. 3rd Nordic High Temp. Symposium (1972) 69 - see also Proc. Plansee-Seminar, Reutte (1971)

8b. Fitzer, E. Schlichting, J. Schmidt, F.K. "High Temp. - High Press." 2 (1970) 553

8c. Fitzer, E. Herbst, H. Schlichting, J. Proc. 4th Intern. Carbon and Graphite Conf. (1974) 401

9. Bonnke, M. Fitzer, E. Ber. Deutsche Keramische Gesellschaft 43 (1966) 180

10. Fitzer, E. CIT 41 (1969) 331

11a. Fitzer, E. Rohm, M. Proc. 4th Intern. CVD Conf., Boston (1973)

11b. Rohm, M. PhD Thesis, University of Karlsruhe (1969)

12. Schlichting, J. PhD Thesis, University of Karlsruhe (1971)

13. Buhler, J.-J. PhD Thesis, University of Karlsruhe, (1976)

14. Schwab, K.-M. "Handbuch der Katalyse" Vol. IV/1, 260, Springer, Wien (1957) see also Fitzer, E. Fritz, W. Springer-Verlag Berlin, Heidelberg, New York, 3. Aufl. (1989) 327

15. Fitzer, E. Kehr, D. Sahebkar, M. CIT 45 (1973) 1244

16. Aggour, L. Fritz, W. CIT 43 (1971) 472

16b. Schoch, G. PhD Thesis, University of Karlsruhe (1990)

17. Aggour, L. Fitzer, E. Ignatiowitz, W. Sahebkar, M. Carbon 12 (1974) 350

18. Fitzer, E. Ignatowitz, E. Sahebkar, M. Prep. Carbon 72, Baden-Baden, (1972), paper 7

19. Fitzer, E. Fritz, W. Kehr, D. VDI-Z 114 (1972) 1221

20. Fitzer, E. Kehr, D. Sahebkar, M. CIT 46 (1973) 1244

21. Fitzer, E. Kehr, D. Sahebkar, M. Dechema (1972)

22. Schmaderer, F. Wahl, G. J. Mat. Sci. 24 (1989) 1141

23. Weiss, R. Private Communication (1991)

24. Stumm, Th. PhD Thesis, University of Karlsruhe (1991)

25. Fitzer, E. Schlesinger, H. Carbon, 3 (1965) 247

26. Fitzer, E. Schlesinger, H. Ber. Deutsche Keram. Gesellschaft 43 (1966)209

27. Fitzer, E. Fritz, W. Rhee, B. High Temp.-High Pressures, 9 (1977) 231

28. Fitzer, E. Fritz, W. Rhee, B. DKG-Ber. Carbon 76, Prep. 551

29. Rhee, B. PhD Thesis, University of Karlsruhe (1970)

30. "Carbon Fibres, Filaments and Composites" : edited by J. L. Figueiredo et al., NATO ASI Series, series E, Applied Sciences, vol. 177, Kluwer Academic Publishers, Dordrecht, Boston, London (1990)

31. Eversole, W.G. (1958) US Patents 3030187,3030188

32. Derjagnin, B. New Scientist (1969) 228

33. Braun, W. PhD Thesis, University of Karlsruhe (1974)

34. Bichler, R. et al. High Temp.-High Press. 21 (1989) 473

35.. Listos, R. High Temp.-High Press. 22 (1990) 99

36. Bhoudina, A. PhD Thesis, University of Karlsruhe - in preparation

37. Bauer, E. Spur, EJ. Schweizer, D.G. J. of Low Temp. Phys. 19 (1975) 189

38. Brennfleck, K. Dietrich, M. Fitzer, E. Kehr, D. Proc. of the 7th Intern. Conf. on CVD, Los Angeles, USA (1979) 300 
39. Schmaderer, F. PhD Thesis, University of Karlsruhe (1990)

39a. Schmaderer, F. lecture - this conference

40. Fitzer, G. Diploma Thesis, University of Karlsrube (1990)

41. Enig, G. Fitzer, E. Kiliani, S.W., Schoch, G. 5th Conf, on Surface Modification Technologies (1991) Birmingham - in preparation

42. Fitzer, E. et al: 22 ETPC Wien 90, High Temp.-High Press., 22 (1991) in print 